OPEN ACCESS

Edited by:

In-Geol Choi,

Korea University, South Korea

Reviewed by:

Song Xiang,

Tianjin Medical University, China

Yuridia Mercado-Flores,

Polytechnic University of

Pachuca, Mexico

*Correspondence:

Dong-Woo Lee

leehicam@yonsei.ac.kr

†These authors have contributed equally to this work

Specialty section:

This article was submitted to Protein Chemistry and Enzymology, a section of the journal

Frontiers in Molecular Biosciences

Received: 30 August 2020 Accepted: 25 November 2020

Published: 17 December 2020

Citation:

La JW, Dhanasingh I, Jang H, Lee SH and Lee D-W (2020) Functional Characterization of Primordial Protein Repair Enzyme M38 Metallo-Peptidase From Fervidobacterium islandicum AW-1.

Front. Mol. Biosci. 7:600634 doi: 10.3389/fmolb.2020.600634

\section{Functional Characterization of Primordial Protein Repair Enzyme M38 Metallo-Peptidase From Fervidobacterium islandicum AW-1}

\author{
Jae Won La ${ }^{1 \dagger}$, Immanuel Dhanasingh ${ }^{2 \dagger}$, Hyeonha Jang ${ }^{3}$, Sung Haeng Lee ${ }^{2}$ and \\ Dong-Woo Lee ${ }^{1 *}$
}

${ }^{1}$ Department of Biotechnology, Yonsei University, Seoul, South Korea, ${ }^{2}$ Department of Cellular and Molecular Medicine, Chosun University School of Medicine, Gwangju, South Korea, ${ }^{3}$ School of Applied Biosciences, Kyungpook National University, Daegu, South Korea

The NA23_RS08100 gene of Fervidobacterium islandicum AW-1 encodes a keratin-degrading $\beta$-aspartyl peptidase (FiBAP) that is highly expressed under starvation conditions. Herein, we expressed the gene in Escherichia coli, purified the recombinant enzyme to homogeneity, and investigated its function. The $318 \mathrm{kDa}$ recombinant FiBAP enzyme exhibited maximal activity at $80^{\circ} \mathrm{C}$ and $\mathrm{pH} 7.0$ in the presence of $\mathrm{Zn}^{2+}$. Size-exclusion chromatography revealed that the native enzyme is an octamer comprising a tetramer of dimers; this was further supported by determination of its crystal structure at 2.6 ̊ resolution. Consistently, the structure of FiBAP revealed three additional salt bridges in each dimer, involving 12 ionic interactions that might contribute to its high thermostability. In addition, the co-crystal structure containing the substrate analog $N$-carbobenzoxy- $\beta$-Asp-Leu at $2.7 \AA$ resolution revealed binuclear $\mathrm{Zn}^{2+}$-mediated substrate binding, suggesting that FiBAP is a hyperthermophilic type-I ladA, in accordance with sequence-based phylogenetic analysis. Indeed, complementation of a Leu auxotrophic $E$. coli mutant strain $(\Delta i a d A$ and $\Delta / e u B$ ) with FiBAP enabled the mutant strain to grow on isoAsp-Leu peptides. Remarkably, LC-MS/MS analysis of soluble keratin hydrolysates revealed that FiBAP not only cleaves the C-terminus of isoAsp residues but also has a relatively broad substrate specificity toward $\alpha$-peptide bonds. Moreover, heat shock-induced protein aggregates retarded bacterial growth, but expression of BAP alleviated the growth defect by degrading damaged proteins. Taken together, these results suggest that the viability of hyperthermophiles under stressful conditions may rely on the activity of BAP within cellular protein repair systems.

\footnotetext{
Keywords: M38 $\beta$-aspartyl peptidase, protein repair, starvation, type-I BAP, hyperthermophile stress responses, keratin degradation, Fervidobacterium islandicum AW-1
}

\section{INTRODUCTION}

Protein homeostasis (proteostasis), a balanced state between folded proteins and protein aggregates, is critical for cellular metabolism, physiology, and normal aging (Hutt and Balch, 2010). To maintain proteostasis, molecular chaperones control the folding of newly synthesized proteins, and the ubiquitin-proteasome 
system degrades misfolded and damaged polypeptides (Hipp et al., 2019). In eukaryotes, damaged proteins destined for degradation are ubiquitinated and subsequently degraded by the $26 S$ proteasome (Goldberg, 2003). Like the ubiquitin-proteasome pathway in eukaryotes, prokaryotes also degrade abnormal proteins through a quality control network (QCN) consisting of chaperones and proteases (Goldberg, 1972; Mogk et al., 2011). To ensure protein homeostasis, bacteria should monitor the folding of proteins and prevent the accumulation of misfolded proteins via coordinated refolding or degradation (Mogk et al., 2011). Misfolded and abnormal proteins are produced for several reasons, including somatic mutations in genes that result in proteins failing to adopt the native folded structure, errors during transcription or translation, failure of the chaperone machinery, mistakes during the post-translational modification of proteins, and structural modifications caused by environmental changes (heat, oxidative agents, $\mathrm{pH}$, or osmotic conditions), and induction of protein misfolding through seeding and crossseeding mechanisms (Visick and Clarke, 1995; Moreno-Gonzalez and Soto, 2011). One of the major modifications of proteins is the deamination of asparaginyl or the isomerization of aspartyl residues through a cyclic intermediate, resulting in aspartyl or isoaspartyl (isoAsp) residues that contribute to inactivation, aggregation, and aging of proteins in tissue (Cournoyer et al., 2005). Indeed, isoAsp formation is associated with abnormal functioning of various proteins, including calmodulin, epidermal growth factor, and ribonuclease (Aswad, 1995). The formation of isoAsp can also decrease the biological activity of a protein drug, alter its susceptibility to proteolytic degradation, and induce autoimmunity (Aswad et al., 2000).

Bacteria possess enzymatic repair systems to prevent conformational damage to proteins resulting from proline isomerization, methionine oxidation, and formation of isoAsp residues (Visick and Clarke, 1995). Protein L-isoAsp Omethyltransferase (PIMT), one of the QCN proteins, is found in most archaea and Gram-negative eubacteria, as well as eukaryotes (Ryttersgaard et al., 2002). PIMT minimizes accumulation of atypical isoAsp residues by methylating the free $\alpha$-carboxyl group of isoAsp residues (Reissner and Aswad, 2003). PIMT-deficient mice accumulate high levels of damaged proteins containing isoAsp residues, resulting in growth retardation and sudden early death (Kim et al., 1997). A similar PIMT protein repair enzyme was identified in the hyperthermophilic bacterium Thermotoga maritima, which grows optimally at $90^{\circ} \mathrm{C}$. Accumulation of proteins with altered aspartyl and asparaginyl residues is believed to be detrimental to cell survival at elevated temperatures. The rate of isoAsp residue formation increases 910 -fold at $90^{\circ} \mathrm{C}$ compared with $23^{\circ} \mathrm{C}$ (Ichikawa and Clarke, 1998); hence, modified or damaged protein (peptide) aggregates should be rapidly digested to prevent cellular damage and to provide a potential nutrient source to support cell survival in harsh environments. However, PIMT alone does not appear to be sufficient to prevent accumulation of protein aggregates due to its low conversion activity (Reissner and Aswad, 2003). Rather, isoAsp peptidase hydrolyzes the peptide bond directly to generate the $\beta$-carboxylate group of Asp (Marti-Arbona et al., 2005a), which is more efficient at handling peptides containing isoAsp residues.

The NA23_RS08100 gene encodes M38 $\beta$-aspartyl peptidase (BAP) in the feather-degrading bacterium Fervidobacterium islandicum AW-1 (Nam et al., 2002; Lee et al., 2015a). Among 57 genes encoding proteases in this organism, the NA23_RS08100 gene is most highly expressed when cells are grown under starvation conditions (Kang et al., 2020), suggesting that in addition to PIMT, the protein encoded by NA23_RS08100 might be involved in degrading isoAsp peptides under stressful conditions. To gain insight into the biological role of BAP as a QCN protein, we functionally and structurally characterized the protein product of the NA23_RS08100 gene in F. islandicum AW-1.

\section{MATERIALS AND METHODS}

\section{Phylogenetic Analysis}

A phylogenetic tree was generated using the maximum likelihood method in MEGA X version 10.0.5, based on multiple sequence alignment of M38 $\beta$-aspartyl peptidase from Fervidobacterium islandicum AW-1 (FiBAP) and homologs sharing $\geq 40 \%$ amino acid sequence identity. A bootstrap consensus tree was inferred from 1,000 replicates. Evolutionary distances were computed using the Poisson correction method and expressed as the number of amino acid substitutions per site. Amino acid sequence alignment was performed using ClustalX software V2.1. Sequence similarities and secondary structure information from aligned sequences were generated using ESPript 3.0 (Robert and Gouet, 2014).

\section{Cloning and Expression of the NA23_RS08100 Gene}

Genomic DNA was isolated from $F$. islandicum AW-1, purified using a genomic DNA extraction kit according to the manufacturer's instructions (Qiagen, Hilden, Germany), and then used as template for PCR amplification. The NA23_RS08100 gene encoding FiBAP was amplified by PCR using forward $\left(5^{\prime}-\right.$ GCTAGCATGATAAAAATTATAAAGAACG-3') and reverse (5'-CTCGAGTCAAAATTCAAAGTTTAAGTTC- $\left.3^{\prime}\right)$ primers (underlined sequences represent the restriction sites for NheI and XhoI). The PCR product was digested with NheI and XhoI and cloned into the pET-28a(+) vector (Novagen, San Diego, CA), yielding pET-FiBAP. The resulting plasmid encodes the target gene fused to a $6 \times$ His-tag at the N-terminus. For expression of recombinant FiBAP, E. coli BL21 (DE3) cells transformed with pET-FiBAP were grown at $37^{\circ} \mathrm{C}$ in $1 \mathrm{~L}$ of Luria-Bertani (LB) medium containing kanamycin $(50 \mu \mathrm{g} / \mathrm{mL})$ to an optical density at $600 \mathrm{~nm}\left(\mathrm{OD}_{600}\right)$ of $0.5-0.8$. After induction with $1 \mathrm{mM}$ Isopropyl-1-thio- $\beta$-D-galactopyranoside (IPTG), cells were grown overnight at $37^{\circ} \mathrm{C}$, then harvested by centrifugation $\left(10,000 \times \mathrm{g}, 20 \mathrm{~min}, 4^{\circ} \mathrm{C}\right)$ and stored at $-80^{\circ} \mathrm{C}$.

\section{Purification of FiBAP}

The harvested cells were resuspended in $20 \mathrm{mM}$ Tris- $\mathrm{HCl}$ buffer containing $500 \mathrm{mM} \mathrm{NaCl}, 5 \mathrm{mM}$ imidazole, and $1 \mathrm{mM}$ phenylmethylsulfonyl fluoride (PMSF) ( $\mathrm{pH}$ 7.9) and disrupted 
by sonication. After centrifugation at $10,000 \times \mathrm{g}$ for $20 \mathrm{~min}$, the supernatant was heated at $60^{\circ} \mathrm{C}$ for $30 \mathrm{~min}$ then centrifuged at $10,000 \times \mathrm{g}$ for $20 \mathrm{~min}$ to remove denatured E. coli proteins. The supernatant was applied to $\mathrm{Ni}^{2+}$-affinity resin $(10 \mathrm{~mL})$ equilibrated with the same buffer, and His-tagged protein was eluted with $20 \mathrm{mM}$ Tris- $\mathrm{HCl}$ buffer containing $500 \mathrm{mM} \mathrm{NaCl}$ and $250 \mathrm{mM}$ imidazole. Samples were loaded on a Superdex 200 10/300 GL column (GE Healthcare, USA) equilibrated with $25 \mathrm{mM}$ Tris- $\mathrm{HCl}$ buffer ( $\mathrm{pH}$ 7.5) containing $150 \mathrm{mM} \mathrm{NaCl}$ (Supplementary Table 1). The major fractions were analyzed by $12 \%$ sodium dodecyl sulfate polyacrylamide gel electrophoresis (SDS-PAGE) and visualized using Coomassie Blue staining.

To monitor the recombinant FiBAP, western blotting was performed using a $6 \times$ His tag monoclonal antibody (ThermoFisher Scientific, USA). Each sample was subjected to $12 \%$ SDS-PAGE, electrophoretically transferred to a polyvinylidene fluoride (PVDF) membrane (Bio-Rad, Hercules, CA, USA), blocked with 5\% skim milk in TBST buffer $(20 \mathrm{mM}$ Tris- $\mathrm{HCl}, \mathrm{pH} 7.5,150 \mathrm{mM} \mathrm{NaCl}$, and $0.05 \%$ Tween 20) at $4{ }^{\circ} \mathrm{C}$ overnight, and incubated with horseradish peroxidaseconjugated $6 \times$ His epitope monoclonal antibody $(1: 1,000$ dilution) for $2 \mathrm{~h}$ at room temperature. The membranes were then washed three times with TBST buffer for $10 \mathrm{~min}$ and were developed using a WESTSAVE Up western blotting detection system (AbFrontier, Seoul, Korea).

\section{Preparation of Recombinant Feather Keratins Expressed in E. coli Cells}

Recombinant feather keratins were prepared as described previously (Jin et al., 2017) and used as native substrates. Briefly, E. coli cells expressing recombinant feather keratins were resuspended in lysis buffer $\left(50 \mathrm{mM} \mathrm{NaH} \mathrm{PO}_{4}, 300 \mathrm{mM}\right.$ $\mathrm{NaCl}, 10 \mathrm{mM}$ imidazole, $1 \mathrm{mM}$ PMSF, $\mathrm{pH}$ 8.0) and disrupted by sonication. After centrifugation at $10,000 \times \mathrm{g}$ for $30 \mathrm{~min}$, expressed keratins in the form of inclusion bodies were resuspended in lysis buffer containing $8 \mathrm{M}$ urea and $1 \mathrm{mM}$ PMSF, incubated on ice for $1 \mathrm{~h}$, and centrifuged at $16,000 \times \mathrm{g}$ for $30 \mathrm{~min}$. Supernatants were filtered through a $0.45 \mu \mathrm{m}$ membrane, then applied to a $10 \mathrm{~mL} \mathrm{Ni-NTA}$ agarose resin column (Qiagen, Germany) equilibrated with lysis buffer containing $8 \mathrm{M}$ urea. Fractions containing unfolded keratins were eluted with $250 \mathrm{mM}$ imidazole, concentrated using an Amicon Ultra-3K device (Millipore, USA), and buffer-exchanged by step-wise dialysis against $50 \mathrm{mM}$ Tris- $\mathrm{HCl}(\mathrm{pH} 8.0)$ at $4^{\circ} \mathrm{C}$. Dialyzed samples were centrifuged at $10,000 \times \mathrm{g}$ for $30 \mathrm{~min}$ to remove insoluble material, and the resulting supernatants containing refolded keratins were concentrated using an Amicon Ultra-3K device (Millipore).

\section{Enzyme Activity Assay}

FiBAP activity was determined by measuring the increase in free amino acids (Rosen, 1957). Reaction mixtures $(0.16 \mathrm{~mL}) \quad$ containing $50 \mathrm{mM} \quad$ 4-(2-hydroxyethyl)-1piperazineethanesulfonic acid (HEPES) buffer ( $\mathrm{pH}$ 8.0), $500 \mathrm{ng} / \mathrm{mL}$ enzyme, and $1 \mathrm{mM} \beta$-Asp-Leu $(\beta$-DL) as a synthetic substrate were incubated at $80^{\circ} \mathrm{C}$ for $15 \mathrm{~min}$. The reaction was stopped by adding trichloroacetic acid (TCA) reagent. After an additional $15 \mathrm{~min}$ incubation at $100^{\circ} \mathrm{C}$ for color development, followed by cooling on ice, the absorbance was measured at $570 \mathrm{~nm}$. One unit of FiBAP activity was defined as the amount of enzyme that produced $1 \mu \mathrm{mol}$ of product per min under the assay conditions (U/mg). Additionally, to assess the proteolytic activity of the purified enzyme, we measured the increase in free amino acids using the ninhydrin assay (Rosen, 1957) with casein and gelatin as substrates.

\section{Biochemical Characterization of FiBAP}

The temperature dependence of FiBAP activity was measured using the standard protocol but the reaction temperatures was varied from 40 to $98^{\circ} \mathrm{C}$. To determine the effect of $\mathrm{pH}$ on FiBAP activity, reaction mixtures $(0.16 \mathrm{~mL})$ were incubated at $80^{\circ} \mathrm{C}$ under standard assay conditions but HEPES buffer was replaced by $50 \mathrm{mM}$ sodium acetate buffer ( $\mathrm{pH}$ 4.0-6.0), HEPES buffer ( $\mathrm{pH}$ 6.0-8.0), borate buffer $(\mathrm{pH} 8.0-10.0$ ), or sodium bicarbonate buffer ( $\mathrm{pH} 9.0-10.0)$. All $\mathrm{pH}$ values were adjusted at room temperature, and $\Delta \mathrm{pK}_{\mathrm{a}} / \Delta \mathrm{Ts}$ (in which the latter term is the change in temperature) for each buffer was taken into account when the results were analyzed.

To determine the kinetic parameters, assays were performed in $50 \mathrm{mM}$ HEPES ( $\mathrm{pH} 8.0$ ) containing $1 \mathrm{mM} \mathrm{CoCl}_{2}, 500 \mathrm{ng} / \mathrm{mL}$ enzyme, and 1-32 mM $\beta$-DL substrate. Reaction mixtures were incubated for $10 \mathrm{~min}$ at $80^{\circ} \mathrm{C}$ and stopped by cooling on ice. Kinetic parameters were obtained by fitting the empirical data to the Michaelis-Menten equation using Origin 8.0 software.

To analyze the effect of metals, purified FiBAP was treated with $20 \mathrm{mM}$ EDTA at room temperature for $2 \mathrm{~h}$ to remove metal ions, followed by overnight dialysis against $20 \mathrm{mM}$ Tris$\mathrm{HCl}(\mathrm{pH} 7.5)$ at $4^{\circ} \mathrm{C}$ with three changes of buffer. The divalent metal ion content of both as-isolated and EDTAtreated samples were determined by high-resolution inductivelycoupled plasma mass spectrometry (ICP-MS) on a PlasmaQuad 3 instrument. To assess the effects of various metal ions on FiBAP activity, the EDTA-treated samples were preincubated with $1 \mathrm{mM} \mathrm{CoCl} 2 \cdot 6 \mathrm{H}_{2} \mathrm{O}, \mathrm{MnCl}_{2} \cdot 4 \mathrm{H}_{2} \mathrm{O}, \mathrm{MgCl}_{2} \cdot 6 \mathrm{H}_{2} \mathrm{O}, \mathrm{CaCl}_{2} \cdot 2 \mathrm{H}_{2} \mathrm{O}$, $\mathrm{ZnCl}_{2} \cdot 6 \mathrm{H}_{2} \mathrm{O}, \mathrm{CuCl}_{2} \cdot 2 \mathrm{H}_{2} \mathrm{O}, \mathrm{FeCl}_{2} \cdot 6 \mathrm{H}_{2} \mathrm{O}$, or $\mathrm{NiCl}_{2} \cdot 6 \mathrm{H}_{2} \mathrm{O}$ for $15 \mathrm{~min}$ at $50^{\circ} \mathrm{C}$. The residual activity was measured in triplicate under standard assay conditions.

\section{Crystallization and Structure Determination of FiBAP}

Preliminary crystallization trials were performed using purified FiBAP $(10 \mathrm{mg} / \mathrm{mL})$ in an appropriate buffer $(20 \mathrm{mM}$ Tris$\mathrm{HCl} \mathrm{pH} \mathrm{7.4,50} \mathrm{mM} \mathrm{NaCl}$ ) mixed with protein crystallization solutions (Hampton Research and Wizard; 1:1 volume ratio) by the hanging drop vapor-diffusion method at $20^{\circ} \mathrm{C}(293 \mathrm{~K})$ as described previously (Lee et al., 2015b). The initial FiBAP crystals were further improved by modifying the Crystal Screen Lite 34 conditions $(0.1 \mathrm{M}$ sodium acetate $\mathrm{pH} 4.6$ and $1 \mathrm{M}$ sodium formate). FiBAP was co-crystallized with substrate analog $\mathrm{N}$ carbobenzoxy- $\beta$-Asp-Leu (Cbz- $\beta$-DL) at a molar ratio of $1: 1.2$, and crystals of the complex were obtained in modified PEG/Ion screen $2-32$ conditions ( $2 \% \mathrm{v} / \mathrm{v}$ tacsimate $\mathrm{pH} 5.0,0.1 \mathrm{M}$ sodium citrate tribasic dihydrate, $\mathrm{pH} 5.6 ; 16 \% \mathrm{w} / \mathrm{v}$ polyethylene glycol 3350). Crystals were soaked for $30 \mathrm{~s}$ in a cryosolution containing 
mother liquor plus $20 \%$ glycerol, then frozen in liquid nitrogen prior to synchrotron radiation diffraction experiments.

X-ray diffraction data were collected from FiBAP crystals on beamline 7A at the Pohang Light source (Pohang, Korea) using an ADSC Q270 detector, with an oscillation of $1.0^{\circ}$ and a $1 \mathrm{~s}$ exposure per frame over a $360^{\circ}$ range at a wavelength of $0.97934 \AA$. Crystals of FiBAP with and without $\beta$-DL as substrate grown using the above conditions diffracted to 2.6 $\AA$ and $2.7 \AA$, respectively. Diffraction data were processed using the HKL-2000 program (HKL Research Inc.). In the case of the ligand-free structure, molecular replacement (MR) was performed with EcIadA (PDB: 1ONW) as the search model using the CCP4 program MOLREP (Vagin and Teplyakov, 2010). The initial model was further refined using the PHENIX (Afonine et al., 2010) and REFMAC5 (Murshudov et al., 2011) programs to achieve a model with $R_{\text {work }}$ and $R_{\text {free }}$ values of 16.9 and $22.1 \%$, respectively. In the case of the Cbz- $\beta$-DL-bound FiBAP diffraction dataset, to enhance the overall data quality, two native datasets of equivalent diffraction limits were combined using the Scale_and_Merge function of the PHENIX suite (Adams et al., 2010). MR was performed for the Cbz- $\beta$-DL-bound FiBAP structure with the refined crystal structure of ligand-free FiBAP as the search model using the Phaser program (McCoy, 2007). The chemical coordination file for $\beta$-DL was built using Coot (Emsley and Cowtan, 2004) and eLBOW (Moriarty et al., 2009). The ligand was fitted into the map, and several rounds of refinement were performed using the REFMAC5 and PHENIX programs, yielding $R_{\text {work }}$ and $R_{\text {free }}$ values of 19.7 and $27.5 \%$, respectively. The structures of FiBAP with and without Cbz- $\beta$-DL have been deposited in the Protein Data Bank (PDB) under accession codes $7 \mathrm{CDH}$ and 7CF6, respectively.

\section{Construction of Leucine Auxotrophic E. coli Mutants}

The leucine (Leu) auxotrophic E. coli BL21 (DE3) strain was constructed by deleting the leuB gene encoding 3-isopropyl malate dehydrogenase, which is involved in leucine biosynthesis, by the RED/ET recombination method using a Quick \& Easy E. coli Gene deletion kit (Gene Bridges) according to the manufacturer's instructions. A functional cassette flanked with FRT and homology arms was generated by PCR using the FRTPGK-gb2-neo-FRT fragment as a template and primers 5'-AGTTGCAACGCAAAGCTCAACACAACGAAAACAACAAGGAAACCGTGTGAAATTAACCCTCACTAAAGGGCGG$3^{\prime}$ (forward) and 5'-GTACACAACGTGAGCGTCGAACAATTTTTCGTATAACGTCTTAGCCATGATAATACGACTCACTATAGGGCTCG-3' (reverse). The kanamycin selection marker was removed by transforming cells with FLP recombinase expression plasmid 706-FLP (Gene Bridges). After selecting mutants lacking the selection marker cassette by streaking each colony on LB agar plates with and without $50 \mu \mathrm{g} / \mathrm{mL}$ kanamycin, deletion of the leuB gene was confirmed by PCR with primers 5'-GCTAACTACAACGGTCGCCGCTTCCACGGCGTC-3' (forward) and 5'-GGCGCGCAGACCATCGAACGCCTGCGGTGAGG-3' (reverse).
For functional complementation of FiBAP, a functional cassette flanked with FRT and homology arms was generated to delete the $\operatorname{iadA}$ gene encoding EcIadA using primers $5^{\prime}$ CATTGCTGTCGATCTGGGTTATGCAGCTTATTGTTTAACAAGGAGTTACCAATTAACCCTCACTAAAGGGCGG-3' (forward) and 5'-TCAGCCGCCCTTGCGGGCATTCTACGTCCATTCGGGCGGCTGACAACCGTTAATACGACTCACTATAGGGCTCG-3' (reverse). In addition, primers 5'-GTCGGTCGCTGCCTGGGGACAGCCGAAGTG- $3^{\prime}$ (forward) and 5'-CTGAGAGTTGCAGCGGCGTTACCTGGCGG-3' (reverse) were used to confirm the iadA deletion mutants.

\section{Complementation of iadA Deletion by FiBAP}

To monitor the growth phenotypes of the Leu auxotrophic E. coli strains harboring the pET28a-FiBAP and the pET28aiadA plasmids, each protein-overexpressing strain was streaked on appropriate minimal M9 agar plates containing $50 \mu \mathrm{g} / \mathrm{mL}$ kanamycin and $1 \mathrm{mM}$ IPTG supplemented with different compositions of amino acids (19 amino acids with and without $\mathrm{Leu}$ ) in the presence and absence of $1.6 \mathrm{mM} \beta$-DL. To investigate the effect of heat shock on bacterial growth retardation, each strain was grown at $37^{\circ} \mathrm{C}$ to an $\mathrm{OD}_{600}$ of $1.2-1.5$ in $\mathrm{LB}$ medium containing kanamycin $(50 \mu \mathrm{g} / \mathrm{mL})$, and then incubated at $44^{\circ} \mathrm{C}$ for $0.5 \mathrm{~h}$ or longer until cells entered the stationary phase.

To determine the total protein content of soluble (supernatant) and insoluble (pellet) fractions, cells were harvested before (mid-exponential phase) and after (stationary phase) heat treatment. The same amount of cells, as judged by the $\mathrm{OD}_{600}$ value, was resuspended in $50 \mathrm{mM}$ Tris- $\mathrm{HCl}$ buffer $(\mathrm{pH}$ 8.0) and disrupted by sonication. After centrifugation at 10,000 $\times \mathrm{g}$ for $30 \mathrm{~min}$, the protein concentration of fractionated samples was determined using the bicinchoninic acid (BCA) assay (Smith et al., 1985), and each subcellular fractions was visualized on the $12 \%$ acrylamide gel for SDS-PAGE analysis.

\section{LC-MS/MS Analysis}

Keratin hydrolysates were analyzed by reversed-phase HPLCESI-MS/MS using a NanoLC-2D Ultra system (Eksigent, Dublin, CA, USA) coupled to a LTQ-XL mass spectrometer (Thermo Fisher Scientific, Bremen, Germany) in direct injection mode. Briefly, after a $5 \mu \mathrm{L}$ injection, keratin hydrolysates were loaded onto a reversed-phase ProteoPepII C18 column $(5 \mu \mathrm{m}, 300 \AA$ pore size, $0.15 \times 25 \mathrm{~mm}$; New Objective IntegraFrit, Scientific Instrument Services, Inc., Ringoes, NJ, USA) and eluted onto a Molex Polymicro Flexible Fused Silica Capillary Tubing (I.D. $75 \mu \mathrm{m}$, O.D. $375 \mu \mathrm{m}$ ) at a flow rate of $0.4 \mu \mathrm{L} / \mathrm{min}$. The gradient consisted of mobile phase A $[0.1 \%$ formic acid $(\mathrm{v} / \mathrm{v})$ in water], mobile phase B $[0.1 \%$ formic acid $(\mathrm{v} / \mathrm{v})$ in acetonitrile], $2 \%$ solvent B (0$1 \mathrm{~min}), 5 \%$ solvent B (1-62 $\mathrm{min}), 35 \%$ solvent B $(62-65 \mathrm{~min})$, $60 \%$ solvent B (65-70 min), and $2 \%$ solvent B in A (70$90 \mathrm{~min}$ ) with a total runtime of $90 \mathrm{~min}$, including mobile phase equilibration.

MS analysis of peptide eluents was performed on a LTQ-XL system (ThermoFisher Scientific) in positive-ion mode with a nano ion spray voltage of $2.3 \mathrm{kV}$, a scan range of $300-1,800(\mathrm{~m} / \mathrm{z})$, 
a curtain gas pressure of $20 \mathrm{psi}$, a nebulizer gas pressure of 6 psi, and an interface heater temperature of $200^{\circ} \mathrm{C}$. Full-scan MS spectra were acquired from 35 precursors selected for MS/MS analysis from the 300 to $1,800 \mathrm{~m} / \mathrm{z}$ range, utilizing a dynamic exclusion of $30 \mathrm{~s}$. The IDA collision energy (CE) parameter script, selecting up to 35 precursors with charge states of +2 to +3 , was employed to automatically control the CE.

Data were processed using MSConvert (ProteoWizard). This software converts raw data (.RAW format) into peak lists (.mgf format). The FASTA database employed contained the Gallus gallus keratin sequence, and this afforded the opportunity to employ the target decoy database search strategy (Elias and Gygi, 2007). Data containing both MS and MS/MS information were uploaded into Xcalibar software (ThermoFisher Scientific) and used to generate MS-extracted ion chromatograms (XICs) for each identified peptide. For the MS-GF search, carbamidomethyl (C) was set as a fixed modification and oxidation (M) was set as a variable modification. The peptide tolerance was $\pm 4.0 \mathrm{Da}$, and the MS/MS tolerance was $\pm 1 \mathrm{Da}$. The software algorithm simultaneously searched all modifications listed in UniMod (http://www.unimod.org/) (Shilov et al., 2007). False discovery rate (FDR) analysis was also performed using integrated tools in PeptideShaker (CompOmics), which generated.mgf files that were subsequently searched against the current G. gallus keratins SwissProt database using MS-GF.

\section{Differential Scanning Calorimetry (DSC) Measurement}

Calorimetric measurements were performed using a VP-DSC microcalorimeter (Microcal Inc., GE Malvern, Worcestershire, $\mathrm{UK})$. All scans were run at $\mathrm{pH} 7.4$ in $10 \mathrm{mM}$ potassium phosphate buffer containing $150 \mathrm{mM} \mathrm{NaCl}$, over a temperature range from 10 to $130^{\circ} \mathrm{C}$ at a rate of $90^{\circ} \mathrm{C} / \mathrm{h}$. The cell volume was $0.8 \mathrm{~mL}$. Potassium phosphate buffer was used for baseline scans, and apparent melting temperature $\left(T_{\mathrm{m}}\right)$ values of FiBAP $(25 \mu \mathrm{M})$ were determined.

\section{Analysis of Isoaspartic Acid Residues}

An ISOQUANT Isoaspartate Detection Kit (Promega) was used for the detection of isoaspartate (isoAsp) according to the manufacturer's instructions. Each cell lysate $(2 \mu \mathrm{g})$ from heat-shocked strains was incubated at $30^{\circ} \mathrm{C}$ for $30 \mathrm{~min}$ in the presence of L-isoaspartyl (isoAsp) methyltransferase (PIMT) and S-adenosyl methionine (SAM) in the reaction buffer, and the stop solution was then added to halt the reaction. The reaction mixture $(40 \mu \mathrm{l})$ was loaded onto a reversed-phase YMC-Triart C18 column $(250 \times 4.6 \mathrm{~mm}$ I.D. S-5 $\mu \mathrm{m}, 12 \mathrm{~nm})$ equilibrated with $90 \% 50 \mathrm{mM}$ potassium phosphate $(\mathrm{pH} 6.2$ ) and $10 \%$ methanol. The amount of isoAsp was determined by quantifying eluted S-adenosyl homocysteine (SAH).

\section{RESULTS}

\section{In silico-Based Annotation of the NA23_RS8100 Gene Product}

To predict the functional role of the NA23_RS8100 gene product, we performed a BLASTP search using the deduced amino acid sequence to identify homologs. Multiple sequence alignment of the NA23_RS8100 gene product with $\beta$-aspartyl peptidases (BAPs) revealed that its amino acid sequence shares high levels of sequence identity with BAP from Fervidobacterium species $(\geq 65 \%)$ and other genera including Thermosipho ( $\geq 55 \%)$, Pseudothermotoga ( $\geq 51 \%)$, Thermotoga ( $\geq 51 \%)$, Clostridium ( $\geq 49 \%)$, Bacillus ( $\geq 47 \%)$, and Enterococcus ( $\geq 49 \%$; Figure 1 and Supplementary Figure 1). In addition, the deduced amino acid sequence of the NA23_RS08100 gene product shares pronounced sequence identity with mesophilic BAPs from Escherichia coli (EcIadA; 39\% sequence identity; PDB:1ONW) and Colwellia pshchrerythraea $34 \mathrm{H}$ (CpIadA; 41\% sequence identity; PDB:5XGW), for which crystal structures are available. Remarkably, all BAP homologs derived from extremophiles belong to the Type I isoaspartyl dipeptidase (IadA) family, members of which possess a conserved Glu residue for metal binding in the active site (Supplementary Figure 1). Moreover, phylogenetic analysis showed that BAP from $F$. islandicum AW-1 (FiBAP) has a highly close evolutionary relationship with homologs from extremophilic Fervidobacterium and Thermosipho, whereas extremophilic FiBAP has diverged away from the Type II IadAs of mesophiles in the order Enterobacteriales and further away from EcIadA and CPIadA members of the BAP family (Figure 1). These results led us to tentatively conclude that the protein encoded by the NA23_RS8100 gene in F. islandicum AW-1 is $\beta$ aspartyl peptidase (subsequently named FiBAP), representing an ancient form of IadA that has diverged from Type II IadA.

\section{Biochemical Characterization of FiBAP}

We successfully expressed the NA23_RS08100 gene as a Cterminal hexahistidine $(6 \times \mathrm{His})$-tagged fusion protein in $E$. coli BL21 (DE3) cells. To facilitate subsequent purification, E. coli lysates were heat-treated to remove most of the endogenous proteins, and the resulting supernatants containing soluble FiBAP were applied to a $\mathrm{Ni}^{2+}$-affinity column. The purified $6 \times$ His-tagged FiBAP fusion protein yields an intact recombinant protein with an estimated $M_{\mathrm{r}}$ of 42,000 by SDSPAGE (Figure 2A). However, size exclusion chromatography using a Superdex 200 column suggested that the native form of FiBAP is as an octameric protein with an apparent $M_{\mathrm{r}}$ of 318,000 (Figure 2B).

Unlike typical endo-proteases, FiBAP displayed minimal activity toward casein and gelatin as substrates, but it was active against $\beta$-Asp-Leu $(\beta$-DL), with an apparent optimal temperature of $80^{\circ} \mathrm{C}$ (Figure 2C) and an apparent optimum $\mathrm{pH}$ of 7.0 at $80^{\circ} \mathrm{C}$ (Figure 2D). To further assess the structural stability of FiBAP, we used DSC to determine the $\mathrm{T}_{\mathrm{m}}$, revealing a major midpoint of the thermal transition $\left(\mathrm{T}_{\mathrm{m}}=96.8 \pm 0.5^{\circ} \mathrm{C}\right)$ and a minor one at $100.4 \pm 1.44^{\circ} \mathrm{C}$ (Figure 2E).

Since EcIadA is a metalloprotease, we performed ICP-MS analysis of as-isolated FiBAP, demonstrating that it contained $\mathrm{Zn}^{2+}(1.14 \pm 0.37 \mathrm{~mol}$ of metal per mol of monomer). To investigate the effects of inhibitors on FiBAP activity, asisolated enzyme was pre-incubated with various inhibitors and its residual activity was measured. Dithiothreitol, PMSF, and Pepstatin A had little inhibitory effect on FiBAP, but $1 \%$ 


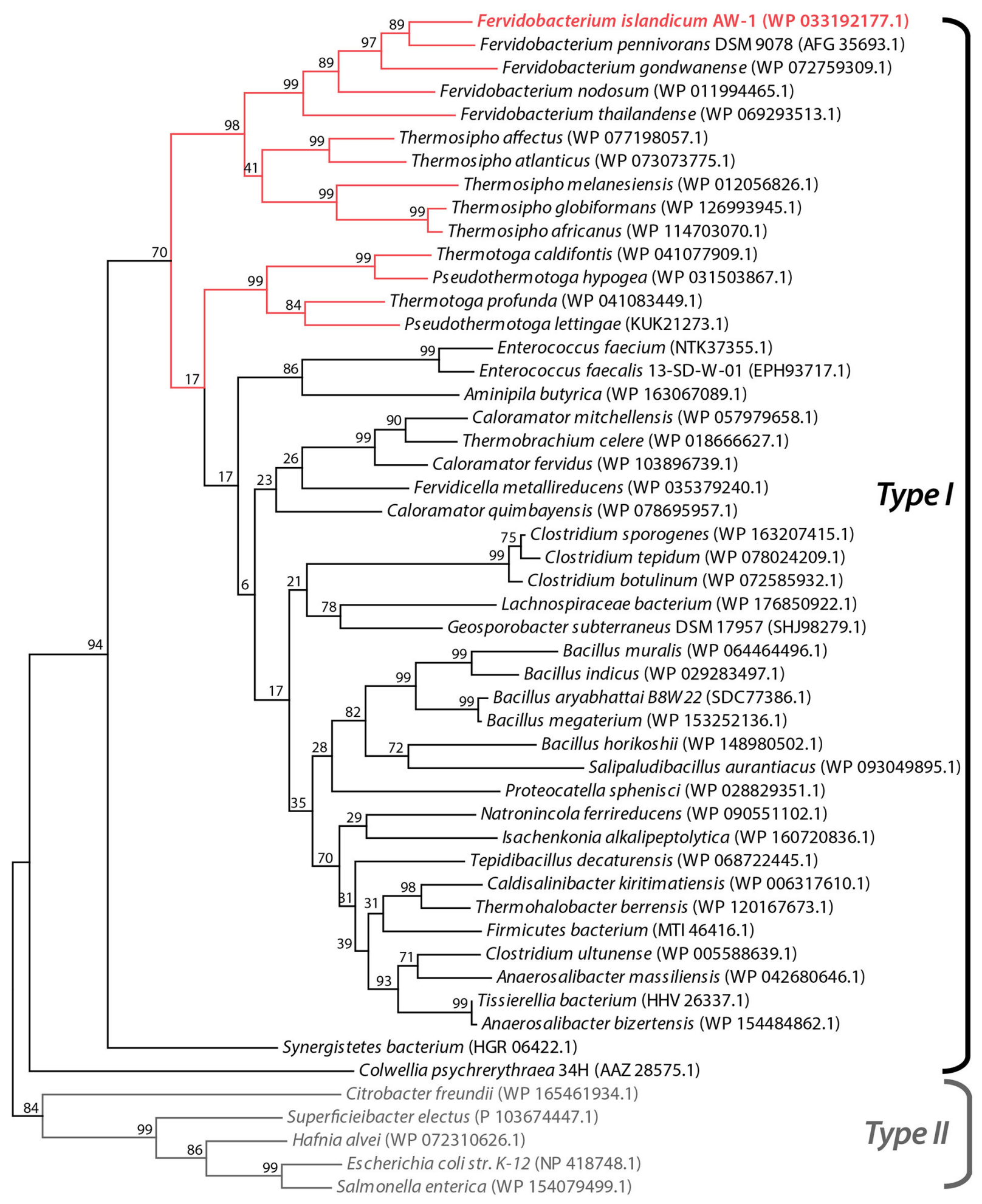

La et al.

FIGURE 1 | Phylogenetic analysis of FiBAP and its homologs. The phylogenetic tree was constructed based on protein sequence alignments of FiBAP and 50 BAP homologs using the maximum likelihood method in MEGAX. Bootstrap values are indicated at the branch points. Red lines indicate BAP derived from hyperthermophilic bacteria. The scale bar indicates a branch length equivalent to 0.2 changes per amino acid. NCBI protein database accession numbers for each individual protein sequence are indicated in parentheses. 


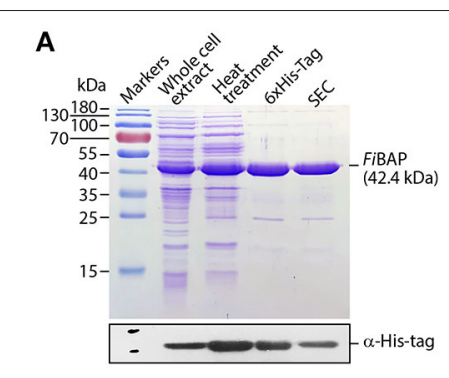

D

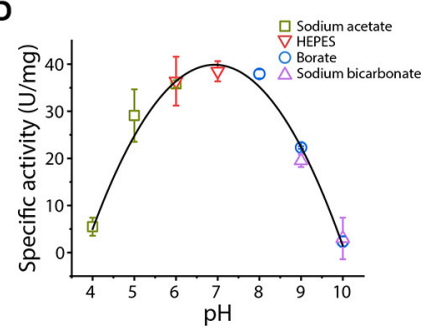

B

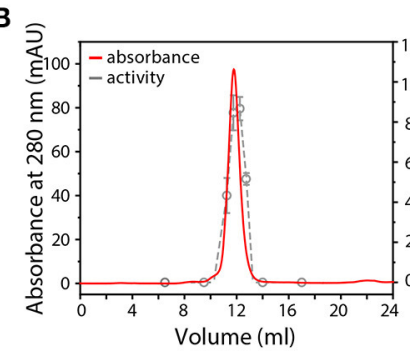

$\mathbf{E}$



C

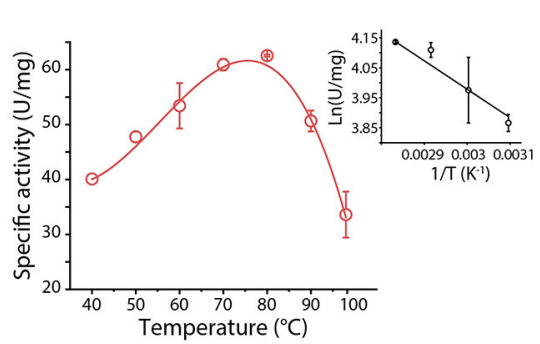

G

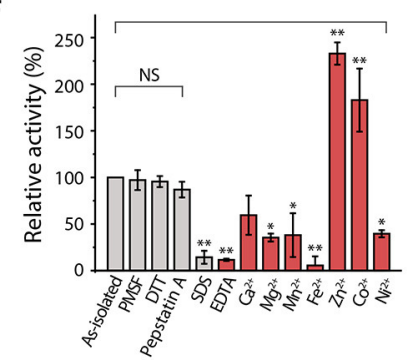

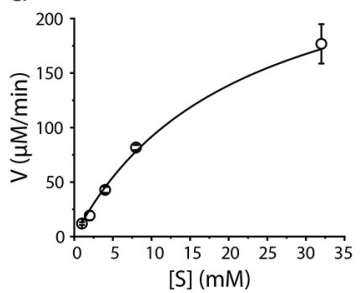

FIGURE 2 | Biochemical properties of FiBAP. (A) Purification of recombinant FiBAP analyzed by 12\% SDS-PAGE. (B) Size-exclusion chromatography of FiBAP using a Superdex 200 pg 10/300 column and the enzyme activity of the eluents. The column was calibrated with blue dextran (2,000 kDa), thyroglobulin (669 kDa), ferritin (440 kDa), aldolase (158 kDa), conalbumin (75 kDa), and ovalbumin (44 kDa) as standards (Supplementary Figure 2). The calibration curve shows Log $M_{\mathrm{r}}$ and $\mathrm{K}_{\mathrm{av}}$ values for each standard protein. (C) Temperature dependence of FiBAP activity. (D) Dependence of FiBAP activity on pH. (E) DSC analysis of FiBAP. (F) Effects of divalent metal ions and inhibitors on FiBAP activity. Group differences were assessed using one-way analysis of variance (ANOVA), followed by Tukey HSD test ( ${ }^{*} p<$ 0.05 and ${ }^{* *} p<0.01$ vs. as-isolated). (G) Kinetic analysis of FiBAP. The kinetic parameters for purified FiBAP were estimated by steady-state kinetics analysis using $\beta$-DL as substrate.

SDS and $1 \mathrm{mM}$ EDTA inhibited enzyme activity (Figure 2F). Subsequently, after a $15 \mathrm{~min}$ preincubation of EDTA-treated and dialyzed FiBAP with various metal ions at $50^{\circ} \mathrm{C}$, the residual activity was measured under standard assay conditions, demonstrating that FiBAP activity was significantly increased in the presence of $\mathrm{Zn}^{2+}$ and $\mathrm{Co}^{2+}$ compared with that in the absence of divalent metal ions, suggesting that this enzyme may be a metalloenzyme.

Additionally, we performed steady-state kinetics analysis of FiBAP with $\beta$-DL as substrate, yielding $K_{\mathrm{m}}$ and $\mathrm{V}_{\max }$ values of $5.23 \pm 1.59 \mathrm{mg} / \mathrm{mL}$ and $286.33 \pm 65.7 \mu \mathrm{M} / \mathrm{min}$, respectively (Figure 2G).

Notably, FiBAP is the most abundant and highly expressed enzyme when $F$. islandicum AW-1 is grown on feathers under starvation conditions (Kang et al., 2020). Although a MEROPS (http://merops.sanger.ac.uk) database search provided some information on hierarchical, structure-based classification of the peptidases, it did not yield the predicted cleavage pattern for M38 BAP. To further investigate the hydrolysates resulting from FiBAP degradation, we performed LC-MS/MS analysis using soluble keratins as native substrates (Supplementary Table 2). Remarkably, all peptides hydrolyzed by FiBAP matched the keratin sequences derived from G. gallus sequences, indicating that FiBAP can cleave not only the peptide bond between Asp and Leu, but also other $\alpha$-peptide bonds between hydrophobic, aromatic, and hydrophilic amino acid residues at the $\mathrm{C}$ terminus (Figure 3), as were the cases of the EcIadA and BAP from rat tissue (Dorer et al., 1968; Gary and Clarke, 1995). This result suggests that FiBAP is a beta-aspartyl peptidase with a relatively broad substrate specificity toward $\alpha$-peptide bonds.

\section{Overall Architecture of FiBAP}

Crystal structures of the ligand-free form of FiBAP and the ligand-bound form bound with $N$-carbobenzoxy- $\beta$-Asp-Leu (Cbz- $\beta$-DL) as a substrate analog were determined at resolutions of 2.6 and $2.7 \AA$, respectively (Table 1). Cbz- $\beta$-DL-free and bound structures belonged to I422 and P22 2 space groups, with one and four subunits in the asymmetric unit, respectively. The overall structure of each monomer can be divided into two distinct domains; an N-terminal $\beta$-sandwich domain (M1-G56; G344-E386) and a C-terminal catalytic domain (L57-K343), that are mainly involved in dimerization and catalysis, respectively (Figure 4A). The $\beta$-sandwich domain located at the N-terminus of the molecule mainly comprises nine $\beta$-sheets $(\beta 1-\beta 6, \beta 17-\beta 19)$ arranged in two layers with $\beta 1, \beta 3, \beta 4$, and $\beta 5$ in one layer and $\beta 2, \beta 6$, and $\beta 17-\beta 19$ in the other layer (Figure 4A). Inter-layer interactions may stabilize the $\beta$-sandwich domain consisting of loops and $\beta$-strands through hydrophobic interactions and a salt bridge between K376 in $\beta 19$ and E44 in $\beta 5$. The catalytic domain at the C-terminus of the molecule folds into a $(\beta / \alpha)_{8}$ triosephosphate isomerase (TIM)-barrel motif. Specifically, eight $\beta$-sheets $(\beta 7-\beta 13)$ surrounded by nine $\alpha$-helices $(\alpha 2-\alpha 10)$ form the central core containing the substrate-binding site harboring two $\mathrm{Zn}^{2+}$ ions (Figure 4A).

A structural similarity search using the DALI server revealed that FiBAP is very closely related to EcIadA, a Type II IadA 
A

Chromosome 2_FK4

1 MRRGSLQALGHSHSSIKASPVPRILTPFSGRLTPPGTLHPTAMSCSNLCRPCGPTPLANS $\Lambda$

61 CNEPCVRQCQDSQVVIQPSTVVVTLPGPILSSFPQNTAVGSSSSAAVGSELSAQGVAISS

121 GGFGFGGLGCFNGWRARYPC

$119-140$

\section{Chromosome 27_FK12}

1 MLWEATEEVYLQSQDMSCYSQCVPCRPCGPTPLASSCNEPCVRQCQNSNVVIEPSPVVVT 60

61 LPGPILSSFPQNTVVGSSTSAAVGSILSSEGVPITSGGFDLSGFGSRYCGRRCPPC

$\frac{1}{74-104} \frac{103-120}{93-120}$

B

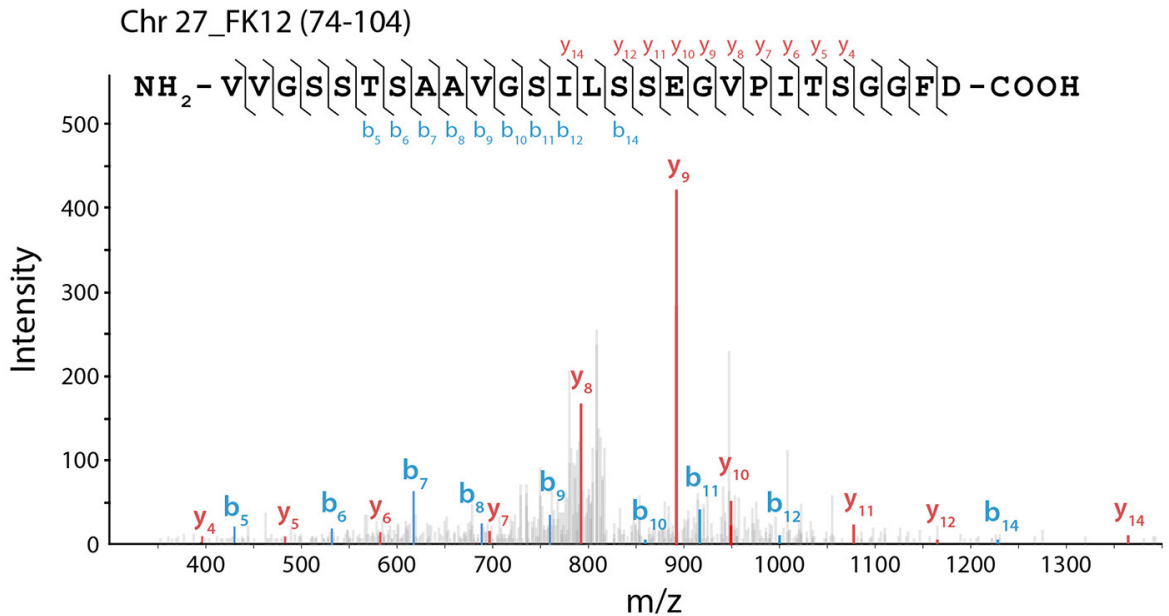

Chr 2_FK4 (74-104)



FIGURE 3 | LC-MS/MS analysis of keratin hydrolysates generated by FiBAP. (A) Keratinolytic peptides matched with soluble Chr2_FK4 and Chr27_FK12 $\beta$-keratins are underlined in red, and their coverage sequences are depicted in bold. Red arrows indicate the putative cleavage site of FiBAP from the identified peptide sequences. Purified recombinant feather keratin and FiBAP were incubated for $18 \mathrm{~h}$ at $80^{\circ} \mathrm{C}$ in $50 \mathrm{mM}$ Tris- $\mathrm{HCl}(\mathrm{pH} 7.5)$. The enzyme/substrate ratio was 1:50 (w/w). (B) Representative MS spectra of keratinolytic peptides and fragment ions of detected peptides from recombinant feather keratins. The identified fragment ions from peptide sequences are labeled in the spectra and indicated on the peptide sequence above. The b (blue) and y (red) peaks correspond to the majority of the $\mathrm{N}$ - and C- terminal ions resulting from fragmentation of each peptide, respectively. 
TABLE 1 | Crystallographic data collection statistics for FiBAP.

\begin{tabular}{|c|c|c|}
\hline & FiBAP (ligand-free) & FiBAP (ligand-bound) \\
\hline PDB ID & $7 \mathrm{CDH}$ & 7CF6 \\
\hline \multicolumn{3}{|l|}{ Diffraction data statistics } \\
\hline Beamline & PLS-7A & PLS-11C \\
\hline Wavelength $(\AA ̊)$ & 0.97934 & 0.98461 \\
\hline Temperature (K) & 100 & 100 \\
\hline Space group & 1422 & $P 22,2$ \\
\hline \multicolumn{3}{|l|}{ Cell parameters } \\
\hline$a, b, c(\AA)$ & $143.9,143.9,119.6$ & $78.6,150.4,151.9$ \\
\hline$\alpha, \beta, \gamma\left({ }^{\circ}\right)$ & $90.0,90.0,90.0$ & $90.0,90.0,90.0$ \\
\hline Data resolution $(\AA ̊)$ & 30.0-2.6 (2.69-2.6) & $47.6-2.7(2.75-2.7)$ \\
\hline Completeness (\%) & $97.7(100.0)$ & $99.7(99.4)$ \\
\hline Redundancy & $22.9(24.6)$ & $10(6.9)$ \\
\hline Total reflections & 439,332 & 466,992 \\
\hline Unique reflections & 18,969 (1908) & 36,967 (1041) \\
\hline$R_{\text {merge }}^{a}$ & $7.3(82.4)$ & $7.4(155.2)$ \\
\hline $\mathrm{CC}_{1 / 2}^{\mathrm{b}}$ & $0.997(0.963)$ & $0.997(0.368)$ \\
\hline Matthew's coefficient $\left(\AA^{3} \mathrm{Da}^{-1}\right)$ & 3.66 & 2.67 \\
\hline Solvent content (\%) & 66.37 & 54.04 \\
\hline Average I/Sigma (I) & $50.3(5.54)$ & $9.0(1.0)$ \\
\hline No. of chains per asymmetric unit & 1 & 4 \\
\hline \multicolumn{3}{|l|}{ Refinement } \\
\hline $\mathrm{R}_{\text {work }}(\%)$ & $19.9(27.9)$ & $19.7(34.5)$ \\
\hline$R_{\text {free }}(\%)$ & $24.4(36.4)$ & $27.5(37.7)$ \\
\hline Protein residues/Ligands & $360 / 0$ & $1497 / 4$ \\
\hline \multicolumn{3}{|l|}{ RMSD } \\
\hline Angles $\left({ }^{\circ}\right)$ & 1.35 & 1.97 \\
\hline Lengths $(\AA ̊)$ & 0.011 & 0.015 \\
\hline Average B-factors $\left(\AA^{2}\right)$ & 40.30 & 49.98 \\
\hline \multicolumn{3}{|l|}{ Ramachandran plot } \\
\hline Most favored regions (\%) & 96 & 92.74 \\
\hline Allowed regions (\%) & 3.43 & 6.25 \\
\hline Outliers (\%) & 0.57 & 1.02 \\
\hline
\end{tabular}

Values in parentheses correspond to the highest resolution shell.

${ }^{a} R_{\text {merge }}=\Sigma_{h k l} \Sigma_{i} / l_{i}(h k l)-<l(h k l)>\mid / \Sigma_{h k l} \Sigma_{i} l_{i}(h k l)$, where $l_{i}(h k l)$ and $<|(h k l)\rangle$ are the intensity of an individual reflection and the mean value of all measurements of an individual reflection, respectively.

${ }^{b} \mathrm{CC}_{1 / 2}$ values are the correlations between intensities from random half-data sets.

enzyme that has evolved in the direction of allowing posttranslational modification (PTM) of the active site for metal binding and catalytic activity (Park et al., 2017). Structural neighbors identified in the FiBAP query structure include IsoAsp dipeptidase, dihydropyrimidinase-related protein, enamidase, allantoinase, and dihydropyrimidinase, all of which are hydrolases. The structural architecture of FiBAP was compared with previously determined structures of homologs (EcIadA and CpIadA). All monomers were superimposed with an average root mean square deviation (RMSD) of $0.705 \AA$ for all $\mathrm{C} \alpha$ atoms (Figure 4B), suggesting that the overall scaffold of FiBAP is similar to that of its homologs. Among these BAPs, structural elements are highly conserved, except for a minor difference in the flexible loop connecting $\beta 4$ and $\beta 5$ (Figures 4A,B), which might be of no discernable biological significance.

Similar to EcIadA (Elias and Gygi, 2007) and CpIadA (Shilov et al., 2007), size-exclusion chromatography (Figure 2B) indicated that FiBAP is an octamer in solution ( $\mathrm{S} 1-\mathrm{S} 8$ in Figure 4C), usually referred to as a "tetramer of dimers" (Figures 4C,D), as supported by symmetry-related molecule analysis. The initial dimer is formed when the $\beta$-sandwich domain of each monomer (Figure 4A) interacts with an adjacent monomer, mainly through hydrophobic interactions involving several residues (I2, I4, V34, V35, V38, L39, F41, and I46) in the loop between $\beta 4$ and $\beta 5$ (upper red box in Figure 4D). Additionally, the substrate-binding cavity of the catalytic domain (Figure 4A) participates in dimerization by providing the second point of contact between adjacent partners through salt bridges. These four salt bridges are formed by E107 ( $\alpha 2), \mathrm{K} 114(\alpha 2)$, R143 ( $\alpha 3)$, and D149 ( $\alpha 3)$ of each monomer of the dimer (lower red box in Figure 4D). Therefore, the hydrophobic interactions between $\beta$-sandwich domains, followed by hydrogen (H)-bonds and salt bridges between catalytic domains of adjacent subunits results in dimer formation (Figure $4 \mathrm{~B}$ and Supplementary Table 3). Remarkably, the corresponding region in structural homologs such as EcIadA and CpIadA does not appear to contain some of these salt bridges because the distances between charged amino acids are $>4 \AA$ in all cases except E114K150 of EcIadA (Supplementary Figure 3B) (Thoden et al., 2003; Park et al., 2017). Hence, we propose that the strong salt bridges may contribute to the thermostability of FiBAP, as reported previously for a hyperthermophilic PIMT, in which deletion of the interfacial residues that interact through salt bridges affected the overall thermostability of the enzyme (Tanaka et al., 2004).

Subsequently, each dimer interacts with two adjacent dimers at three contact points (boxed in Figure 4E) to form a biologically active octamer that includes two contact points (S2-S4 interface and S1-S3 interface in Figure 4C) between similar structural elements $\alpha 4, \alpha 5$ of one dimer, and loops T213-L220, G95-L106, and I159-L169 of the adjacent dimer. We identified additional salt bridges formed at this interface between residues R174 $(\alpha 4)$, D178 ( $\alpha 4)$, and E214 ( $\alpha 5)$ with E171, R131, and R201, respectively (pink and purple boxes in Figure 4E). However, these corresponding residues are conserved and form salt bridges in both EcIadA and CPIadA, revealing their significance in the formation of a stable quaternary structure. In addition, the third contact point (S2-S3 interface) at the dimer-dimer interface is mainly comprised of $\mathrm{H}$-bonds formed between interfacial residues (brown box in Figure 4E). These interactions at different contact points are required in BAPs for their overall stability and to maintain their high oligomeric state.

The ligand-free model included most amino acids except for residues D254-R259 and P290-L302, corresponding to the flexible loops in the molecule (Figure 4A). Intriguingly, the ligand-bound model included obvious electron density corresponding to loop P290-L302 between $\beta 14$ and $\beta 15$, which might have been stabilized upon ligand binding (Figure 5A). By contrast, loop D254-R259 of the Cbz- $\beta$ DL-bound FiBAP structure remained disordered. Remarkably, 

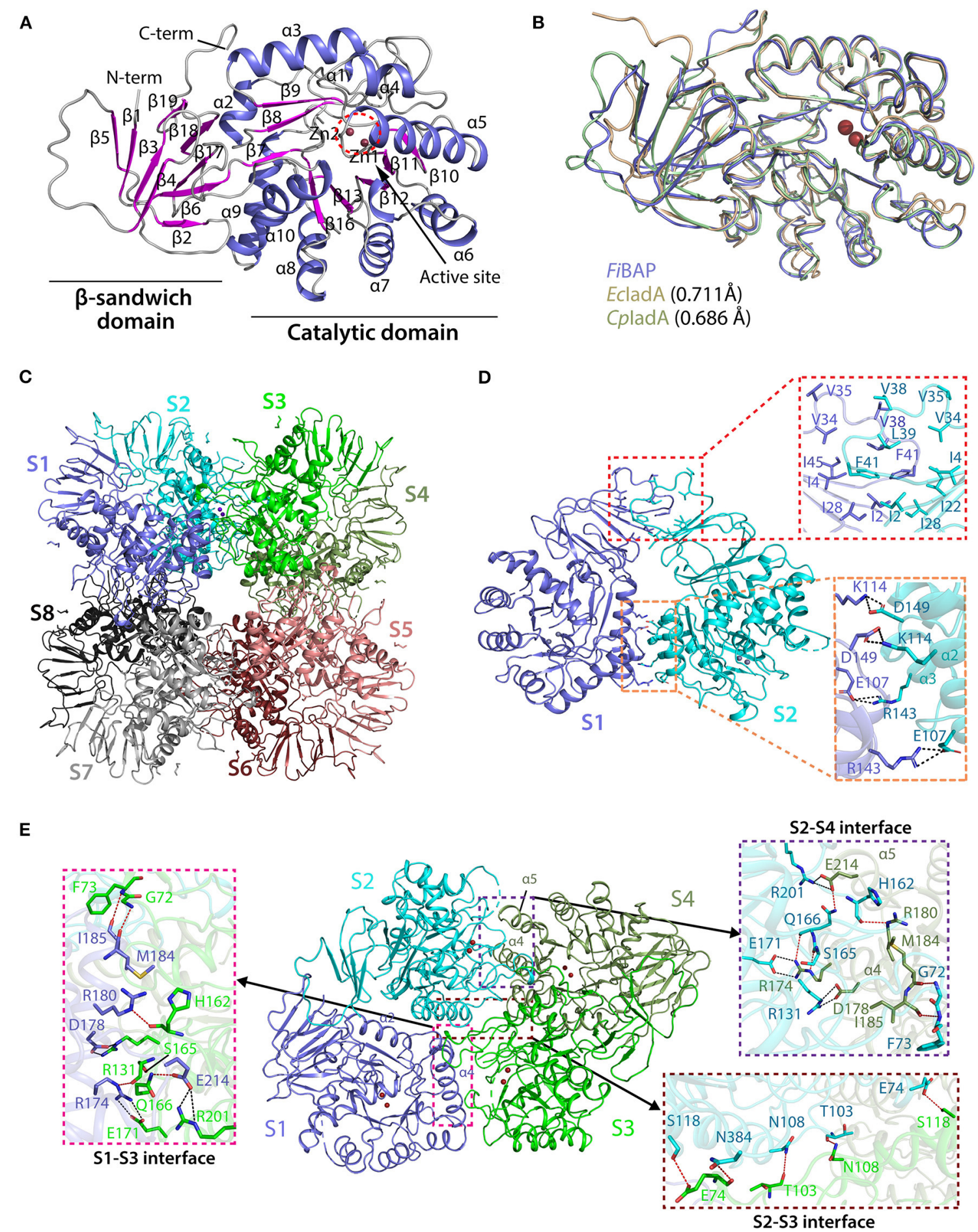

FIGURE 4 | Crystal structure of FiBAP. (A) Domain structure of monomeric FiBAP. The monomeric subunit of FiBAP consists of two domains; an N-terminal $\beta$-sandwich domain and a C-terminal catalytic domain. The structural elements from the $\mathrm{N}$ - to $\mathrm{C}$ - termini of the protein are labeled. The active site (marked as a dotted red circle) contains two zinc metals (Zn1 and Zn2) located in the catalytic domain. (B) Structural alignments of FiBAP with structural homologs EcladA (PDB ID 1ONW) and CpladA (5XGW). RMSD values are indicated in parentheses. (C) Quaternary structure of FiBAP comprising dimers of two tetramers. Symmetry-related molecule analysis reveals FiBAP to be an octamer of eight subunits (S1-S8, subunits colored differently). (D) Interactions at the interface between each subunit in a dimer. Dimers formed from two subunits (S1 and S2) are shown. The top red box shows hydrophobic interactions between $\beta$-sandwich domains, and the bottom salmon box shows salt bridges formed between catalytic domains of each subunit. (E) Dimer-dimer interactions. Interface interactions between the S1-S2 dimer (slate blue and cyan) and the S3-S4 dimer (green and smudge) are shown. The molecular interactions at three contact points, the S2-S4 interface (purple box), the S2-S3 interface (brown box), and the S1-S3 interface (magenta box), are shown in zoomed representation. 


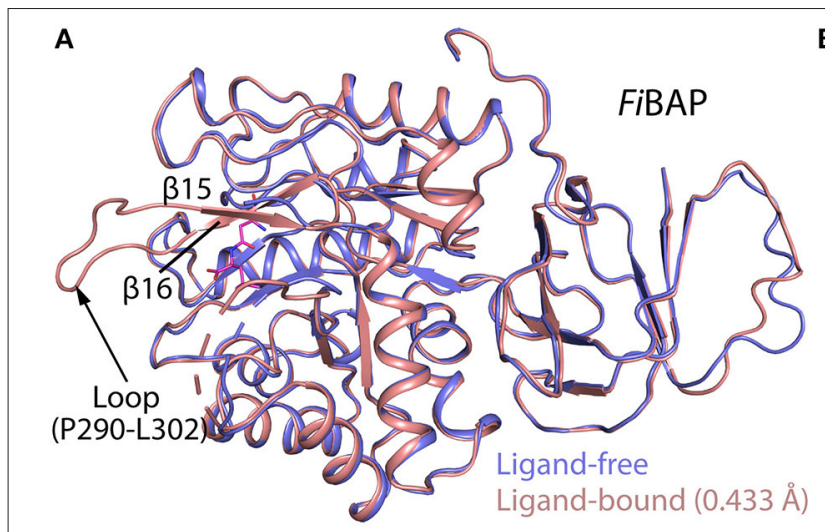

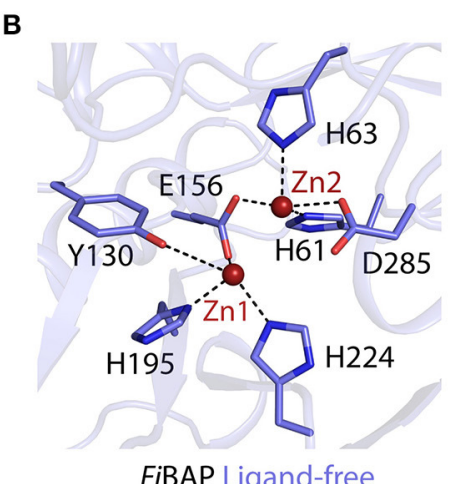

FiBAP Ligand-free



E
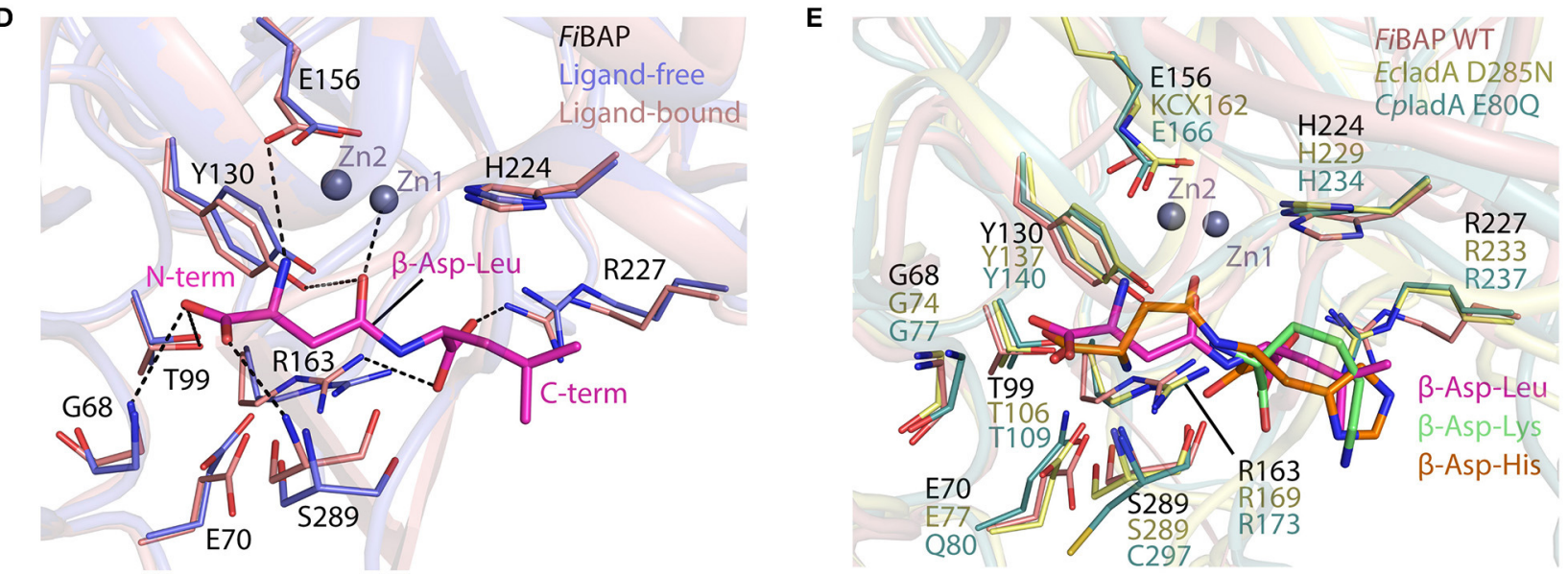

FIGURE 5 | Comparison of ligand-bound and ligand-free structures of FiBAP. (A) Alignment of ligand-bound and ligand-free FiBAP monomers. Note that the P290-L302 loop is stabilized in the ligand-bound structure but not in the ligand-free model. (B) The active site of ligand-free FiBAP containing binuclear zinc metal ions. Residues coordinating the metals are represented as sticks and $\mathrm{H}$-bonds are shown as dotted lines. (C) The active site of ligand-bound FiBAP. The 2 Fo-FC electron density maps of $\mathrm{Zn}^{2+}$ ions and $\beta$-DL are contoured at $1 \sigma$ and colored blue. Residues of FiBAP interacting with metal ions and $\beta$-DL are depicted as sticks. $\mathrm{Zn}^{2+}$ ions are represented as purple spheres and the bound $\beta$-DL is shown as magenta sticks. Ligands and side chains are colored by atom type (oxygen in red, nitrogen in blue, phosphorous in orange). (D) Comparison of residues coordinating the ligand between ligand-free and ligand bound models. Interactions between ligand-bound FiBAP residues and atoms of the ligand are shown as dotted lines. (E) Comparison of the ligand-binding residues of FiBAP bound to $\beta$-DL with their counterparts in ligand-bound homologs ECladA (PDB_1YBQ) and CpladA (PDB_5XGX). Conformational changes in side-chains are indicated. Residues coordinating the ligand are highly conserved among BAPs.

the Cbz- $\beta$-DL-bound FiBAP structure aligned with the ligandfree model with an RMSD of $0.433 \AA$, despite the good superimposition of the structural elements (Figure 5A). Such an unusually high RMSD value might be ascribed to the transformation of the missing loop (P290-L302) in the ligandfree structure into two stable antiparallel $\beta$-sheets ( $\beta 14$ and $\beta 15$ ) in the ligand-bound structure (Figure 5A). Since this stabilized loop is located next to the substrate-binding site, it might function as a gate for substrate entry and/or product release (Park et al., 2017). Intriguingly, the crystal structure of FiBAP bound to Cbz- $\beta$-DL included distinct electron density only for the $\beta$-DL moiety lacking carbamazepine $(\mathrm{Cbz})$ in the active site (Figure 5C).

\section{The Active Site of FiBAP}

The substrate-binding site of BAPs, referred to as the "binuclear zinc center," is located beneath the $(\beta / \alpha) 8$ TIM-barrel motif of the catalytic domain, and comprises two $\mathrm{Zn}^{2+}(\mathrm{Zn} 1$ and $\mathrm{Zn} 2)$ ions $3.2 \AA$ apart from each other (dotted circle in Figure 4A). $\mathrm{Zn} 1$ is coordinated by E156, H195, and H224 residues, while Zn2 is bound by H61, H63, E156, and D285 (Figure 5B). In the metal coordination network, $\mathrm{Zn} 1$ interacts with $\mathrm{Zn} 2$ via E156 (Figure 5B). By contrast, a carbamylated lysine residue (KCX162) in Type-II EcIadA binds two positively charged Zn ions, similar to E156 in Type-I CpIadA (Figure 5E) (Thoden et al., 2003; Park et al., 2017). In addition, E156 in FiBAP forms a cis-peptide bond with G155 in the loop between $\alpha 4$ and $\beta 10$, which is conserved in the corresponding loop of CpIadA between G165 and E166. The cis-peptide bond favors loop bending in FiBAP, which positions E156 toward the metal, as opposed to the carbamylated lysine (KCX162) in EcIadA, suggesting that FiBAP belongs to the Type-I IadAs.

There is no significant perturbation in the coordination of the binuclear zinc center in the Cbz- $\beta$-DL-bound FiBAP structure 


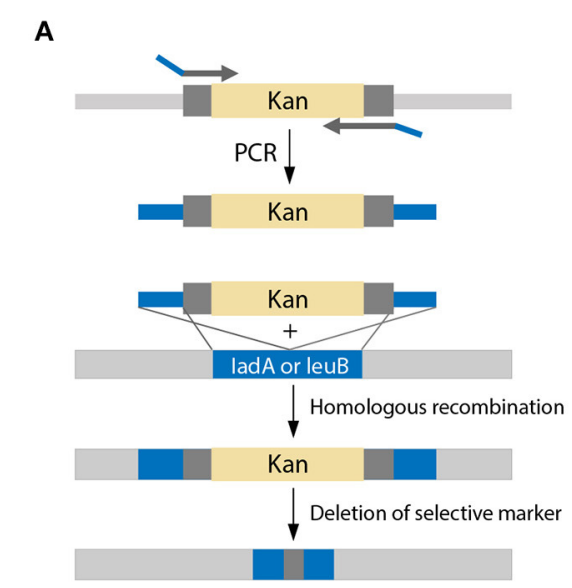

C
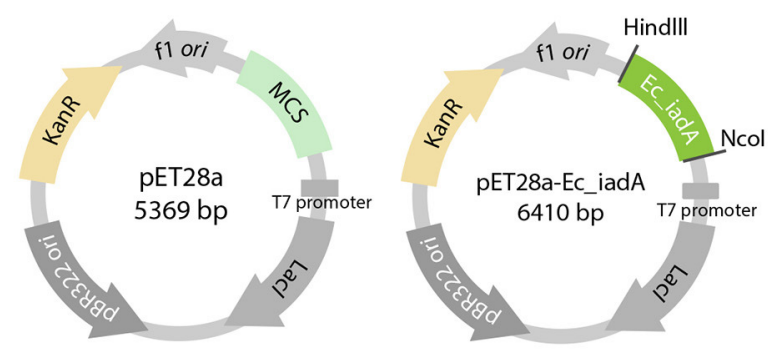

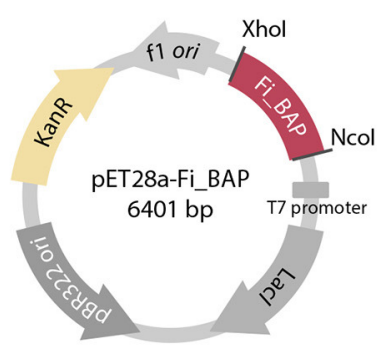

B



D

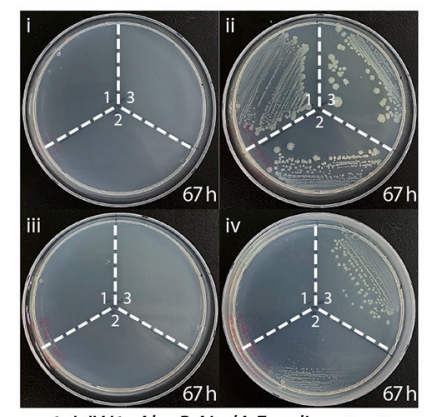

1. LJW1: $\triangle$ leuB $\triangle$ iadA E. coli mutant 2. LJW2: pET28a-Ec_iadA in LJW1

3. LJW3:pET28a-Fi_BAP in LWW1

FIGURE 6 | FiBAP complementation assay of the Leu auxotrophic leuB iadA E. coli double mutant grown on isoAsp peptides. (A) Strategy for obtaining the Leu auxotrophic $\triangle$ leuB $\triangle i$ iadA E. coli double mutant using the RED/ET recombination method. (B) Comparison of growth phenotypes for three E. coli mutant strains (LJW1, the $\triangle$ leuB $\triangle i a d A$ double mutant; LJW2, the LJW1 strain harboring the pET28a-ladA overexpression plasmid; and LJW3, the LJW1 strain harboring the pET28a-FiBAP overexpression plasmid) grown in four different types of medium: (i) M9 minimal medium (M9); (ii) M9 minimal medium containing 20 amino acids (M9-20aa); (iii) M9 minimal medium containing 19 amino acids (Leu- ${ }^{-}$M9-19aa); and (iv) M9 minimal medium containing 19 amino acids (Leu-) and $1.6 \mathrm{mM} \beta$-Asp-Leu (M9_19aa_ $\beta$-DL). Expected growth phenotypes are marked as + or -. (C) Schematic representation of plasmid construction for recombinant proteins. Genes encoding EcladA and FiBAP were ligated into the pET28a expression vector digested with appropriate restriction enzymes. (D) Photographs of three E. coli mutant strains on various $\mathrm{M} 9$ plates after a $67 \mathrm{~h}$ incubation at $37^{\circ} \mathrm{C}$.

(Figure 5C). However, structural comparison of the residues around the ligand-binding site reveals subtle changes of $\sim 1 \AA$ in the side-chain conformations of some residues (G68, E70, Y130, R163, R227, and S289) between Cbz- $\beta$-DL-free and bound forms (Figure 5D). Residues such as Y130, G68, and S289 are placed closer to the ligand than those in the ligandfree structure, thereby assisting coordination and stabilization, while R227 and R163 move away to provide space for ligand binding. Notably, the role of the conserved Y130, which interacts with the $\mathrm{O} 06$ atom of the substrate, has been studied, and the Y137F mutation in EcIadA (corresponding to Y130 in FiBAP) reduced the rate of catalysis by three orders of magnitude (MartiArbona et al., 2005b). Accordingly, the conserved Y130 in FiBAP not only contributes to stabilization of the bound substrate, but also acts as a Lewis acid with the phenolic hydroxyl group of its side chain during hydrolysis of the peptide bond adjacent to Asp of the dipeptide (Marti-Arbona et al., 2005a; Park et al., 2017). The other surrounding residues that help to stabilize the bound Cbz- $\beta$-DL are the amino groups of main-chain residues S289 and G68, while T99 interacts with O04 and O05 atoms of the side-chain of the Asp residue of $\beta$-aspartyl leucine to stabilize the N-terminus of the dipeptide during substrate recognition. Additionally, R163 and R227 interact with O01 and $\mathrm{O} 03$ atoms and stabilize the C-terminal end of the peptide. When the substrate is recognized and stabilized, other residues such as E156, Y130, and E70 partake in acid-base catalysis during cleavage of the peptide bond via zinc metal ions $\mathrm{Zn} 1$ and $\mathrm{Zn} 2$ (Figure 5D). As stated above, all residues involved in the recognition and catalysis of a substrate are highly conserved among homologs (Figure 5E). Intriguingly, the ligand-bound structures of EcIadA and CPIadA were only obtained following mutation of conserved residues involved in metal coordination and catalysis (D285N and E80Q, respectively). By contrast, the structure of Cbz- $\beta$-DL-bound FiBAP was determined directly from wild-type FiBAP. This observation may indicate that the crystallization conditions (temperature $<20^{\circ} \mathrm{C}$ and $\mathrm{pH}<\mathrm{pH}$ 5) 
A

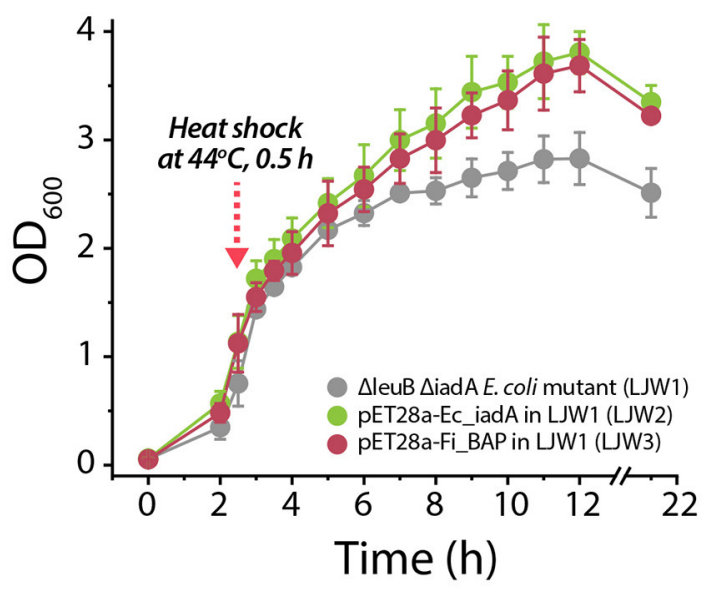

B

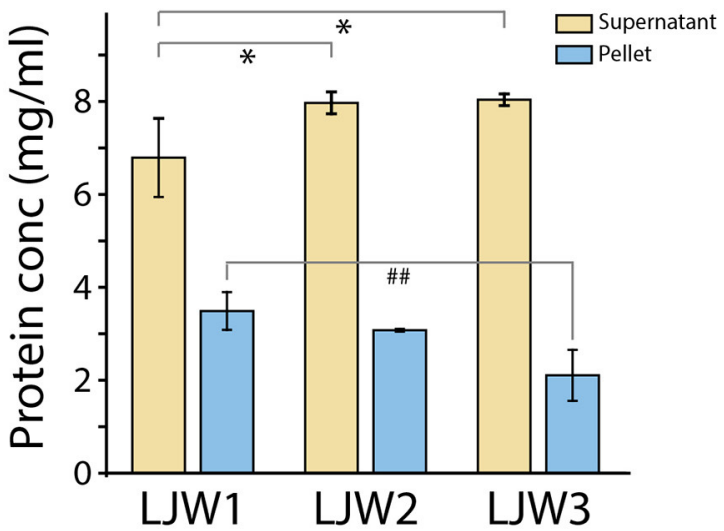

C

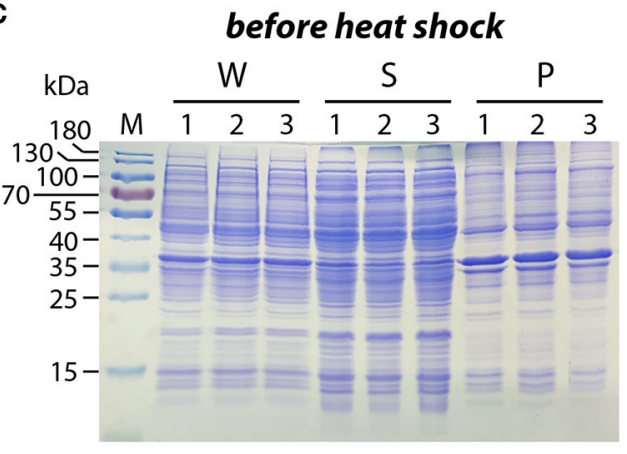

after heat shock

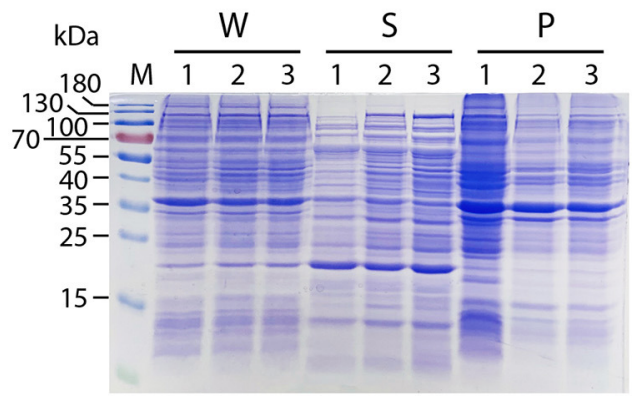

W : whole cell extracts

$S$ : supernatant

$P$ : pellet

$M:$ markers

1 : LJW1

2 : LJW2

3: LJW3

FIGURE 7 | Bacterial growth and protein pattern analysis after heat treatment. (A) Growth curve of E. coli mutant strains (LJW1, LJW2, and LJW3) in LB media at $37^{\circ} \mathrm{C}$. Heat shock treatment was performed at $44^{\circ} \mathrm{C}$ for $30 \mathrm{~min}$ when cells reached the mid-exponential phase $\left(\mathrm{OD}_{600}\right.$ of $\left.1.0-1.5\right)$. (B) Quantification of soluble (supernatant) and insoluble (pellet) protein in heat-treated cells. Group differences were assessed using one-way analysis of variance (ANOVA), followed by LSD test $\left({ }^{*} p<0.05\right.$ vs. WT supernatant and ${ }^{\# \#} p<0.01$ vs. WT pellet). (C) Comparison of whole protein, soluble (supernatant) protein, and insoluble (pellet) protein in heat-treated and non-heat-treated cells by SDS-PAGE analysis.

could have inactivated the thermostable FiBAP enzyme, favoring formation of the substrate $(\beta$-DL)-bound complex structure without being cleaved, as seen in the electron density map (Figure 5C).

\section{Complementation of a Leucine Auxotroph by FiBAP}

To validate whether FiBAP can cleave $\beta$-DL in vivo, we constructed a Leu auxotrophic E. coli BL21 (DE3) strain by deleting the leuB gene encoding 3-isopropylmalate dehydrogenase and the iadA gene encoding BAP in E. coli (Figure 6A). We presumed that the hydrolysis of $\beta$-DL by FiBAP could provide Leu as a nutrient for the Leu auxotrophic E. coli mutant, thereby supporting its growth on M9 minimal medium lacking Leu (Figure 6B). As expected, the $\triangle l e u B$ and $\triangle i a d A$ double mutant grew in M9 medium supplemented with 20 amino acids, but did not grow in M9 medium containing 19 amino acids without Leu (Leu ${ }^{-}$; Figure 6D). Next, to investigate the effect of overexpression of FiBAP and EcIadA on bacterial growth, we constructed the pET28a-Ec_iadA and pET28aFi_BAP vectors (Figure 6C) and heterologously expressed the FiBAP and iadA genes in $\triangle l e u B$ and $\triangle i a d A$ double mutants of $E$. coli BL21 (DE3), respectively. The $\triangle$ leuB $\triangle i a d A$ mutant did not grow on M9 medium supplemented with 19 amino acids (Leu ${ }^{-}$) in the presence of $\beta$-DL during 3 days of incubation, whereas the $\triangle l e u B \triangle i a d A$ double mutant harboring the pET-iadA plasmid grew on M9 medium with 19 amino acids ( $\mathrm{Leu}^{-}$) supplemented with $\beta$-DL, as described previously (Marti-Arbona et al., 2005a). Remarkably, the double mutant containing the pET-FiBAP plasmid could also grow on M9 medium with 19 amino acids $\left(\mathrm{Leu}^{-}\right)$in the presence of $\beta$-DL even at a suboptimal temperature for FiBAP (Figure 6D). This result strongly indicates that FiBAP can also cleave the $\beta$-DL dipeptide to facilitate Leu utilization for bacterial growth, suggesting that FiBAP activity enables $E$. coli to utilize $\beta$-aspartyl peptides as nutrient sources for cell growth.

Accordingly, we hypothesized that heat stress may cause accumulation of misfolded and/or aggregated polypeptides, including the formation of isoAsp residues, resulting in cellular 

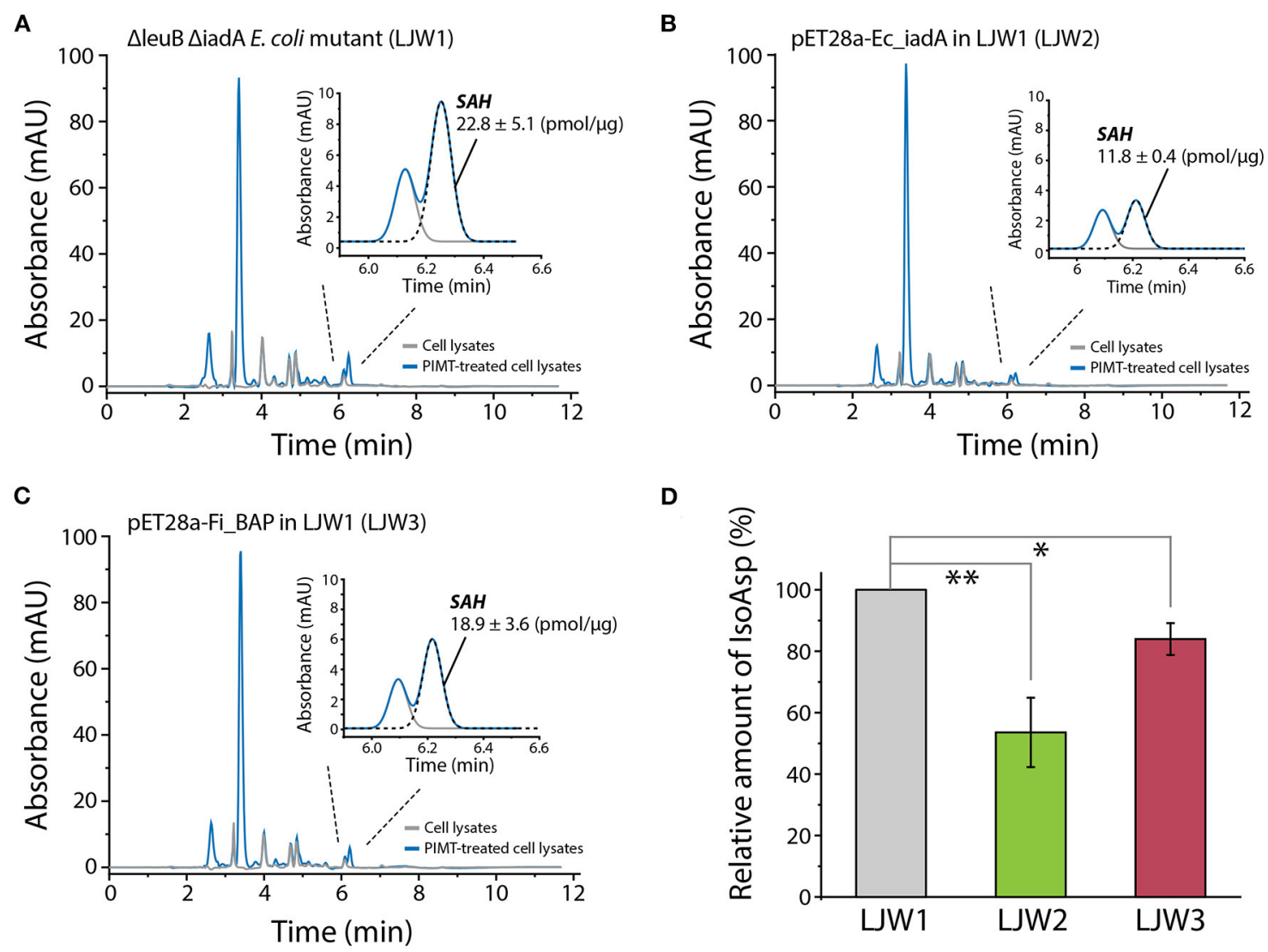

FIGURE 8 | RP-HPLC analysis of SAH for quantification of isoAsp residues in heat-shocked LJW1, LJW2, and LJW3 strains. (A-C) RP-HPLC analysis of SAH in LJW1, LJW2, and LJW3 strain and quantification of isoAsp by calculating the SAH peak area. (D) Relative amount of isoAsp in each heat- treated cell. Group differences were assessed using one-way analysis of variance (ANOVA), followed by LSD test [** $p<0.01$ and ${ }^{\star} p<0.05$ vs. WT (LJW1)].

growth retardation. If so, then overexpression of FiBAP may alleviate the bacterial growth defect. To validate this, we monitored the growth profiles of the $\triangle l e u B \triangle i a d A$ double mutant grown on LB medium with and without FiBAP upon heat shock at $44^{\circ} \mathrm{C}$. Consequently, after a 30 min heat shock treatment, the growth rate and cellular production of the $\triangle l e u B \Delta i a d A$ mutant were decreased by $30 \%$ (based on the $\mathrm{OD}_{600}$ value) compared with those of mutants expressing FiBAP and EcIadA, respectively (Figure $7 \mathbf{A}$ ). In addition, when expressing BAP, the $\triangle l e u B \Delta$ iadA mutant exhibited a $15-40 \%$ decrease in the total protein concentrations of pellets, whereas the concentrations of soluble cytosolic proteins were increased by $20 \%$ (Figure 7B). Furthermore, differential protein pattern analysis by SDS-PAGE clearly indicated that expression of FiBAP could affect the soluble cytosolic protein profiles of the mutant E. coli strains, suggesting that abnormal proteins including isoAsp residues could be efficiently degraded by BAP activity under heat stress conditions (Figure 7C).

Finally, to investigate whether overexpression of FiBAP and $E c$ IadA can reduce the isoAsp-containing protein aggregates within cells, we determined the concentration of S-adenosyl homocysteine (SAH) as the PIMT-mediated by-product derived from the isoAsp-containing peptides in heat-treated mutant strains. Indeed, RP-HPLC analysis of cell lysates demonstrated that the concentrations of $\mathrm{SAH}$ in both mutants expressing FiBAP and EcIadA were lower by 20 and $50 \%$, respectively, than that of the $\triangle l e u B \triangle i a d A E$. coli mutant (LJW1) negative control (Figures 8A-C). These results indicate that the relative amount of isoAsp-containing proteins was decreased significantly in mutants overexpressing EcIadA (LJW2) or FiBAP (LJW3) compared with WT (LJW1) (Figure 8D), suggesting that BAP can hydrolyze isoAsp peptide bonds in the protein aggregates, and thereby alleviate the bacterial growth defect under heat shock conditions.

\section{DISCUSSION}

Protein folding and misfolding are critical for correct cellular function and regulation. Indeed, compelling evidence suggests that misfolded and damaged protein aggregates contribute to cell dysfunction and tissue damage, leading to various diseases (Dobson, 2003; Goldberg, 2003). For example, misfolding of amyloidogenic proteins is strongly associated with the pathogenicity of neurodegenerative diseases such as Alzheimer's, Parkinson's, and Huntington's diseases, and AA amyloidosis. 
Even metabolic syndromes such as type 2 diabetes can be triggered by misfolded protein aggregates (Moreno-Gonzalez and Soto, 2011). It has been reported that up to $30 \%$ of newly synthesized proteins may be misfolded and/or aggregated due to errors in translation or post-translational modifications, including the formation of abnormal amino acid residues (Schubert et al., 2000). In particular, unwanted protein aggregates resulting from the formation of isoAsp residues are an example of spontaneous age-related protein damage in cells, and their degradation and/or removal via deamination and dehydration is essential to prevent cellular cytotoxicity and aging (Ogé et al., 2008). To ensure cellular viability in response to starvation, organisms also tend to preserve protein homeostasis through protein repair systems using several strategies such as refolding, degrading, or sequestrating misfolded polypeptides (Goldberg, 1972; Finn and Dice, 2006; Chen et al., 2011).

In extremophiles thriving under harsh environments, in which proteins are vulnerable to protein inactivation and aggregation, cellular protein repair systems play a pivotal role in protein quality control (PQC) to support cellular integrity and survival (De Castro et al., 2006; Chen et al., 2011; Coker, 2019). In the present study, we functionally characterized the hyperthermophilic M38 $\beta$-aspartyl peptidase FiBAP, a protein repair enzyme involved in hydrolysis of isoAsp residue-containing peptides in $F$. islandicum AW1. Since the extremely thermophilic $F$. islandicum AW-1 belongs to the order Thermotogales, an ancient branch of the bacterial kingdom, this bacterium possesses primordial characteristics, making it an excellent model system for investigating how extremophiles have evolved mechanisms to prevent protein damage and/or denaturation under harsh environments (Singleton and Amelunxen, 1973). Although several functional studies on BAPs from mesophilic organisms have been reported, including human (Ryttersgaard et al., 2002), E. coli (Marti-Arbona et al., 2005b), and Colwellia psychrerythraea (Marti-Arbona et al., 2005b; Park et al., 2017), hyperthermophilic homologs remain uncharacterized.

Phylogenetic analysis based on the primary sequences of its homologs revealed that FiBAP is distantly related to Type II IadA enzymes, suggesting that FiBAP belongs to an ancient form of the BAP family in microorganisms (Figure 1 and Supplementary Figure 1). Our detailed characterization revealed that FiBAP is a hyperthermophilic BAP with a $\mathrm{T}_{\mathrm{m}}$ value of $96.8^{\circ} \mathrm{C}$ in the presence of $\mathrm{Zn}^{2+}$ that forms a tetramer of dimers (Figure 2), consistent with the first crystal structures of octameric Cbz- $\beta$-DL-free and -bound BAPs, and size-exclusion chromatography and symmetry-related molecule analysis (Figures 2B, 4C). The octameric state of FiBAP was compared with the quaternary structures of structural homologs of EcIadA and CpIadA (Supplementary Figure 3A), indicating no significant difference in their overall architecture (Supplementary Figure 3A). Although the crystal structure of FiBAP superimposed well with those of mesophilic EcIadA and CpIadA (Figure 4B), its mesophilic counterparts do not appear to include several of the strong salt bridges (Supplementary Figure 3B). Remarkably, the catalytic domain of FiBAP participates in dimerization through salt-bridges via
R143, K114, E107, and D149 from each monomer, and this is largely responsible for the high thermostability (Figure 4). This observation is consistent with the study of a hyperthermophilic PIMT, in which mutation of the interfacial residues (D204 and D205) to alanine significantly affected thermostability (Gary and Clarke, 1995). Regarding substrate recognition and ligand stabilization, residues such as G68, T99, Y130, and S289 are highly conserved among all homologs (Figure 5E). Notably, residues T99 and S289 appear to be involved in recognition of the N-terminal iso-Asp side chain of the substrate, similar to the roles played by T57 and S59 in protein isoAsp methyltransferase (PIMT) that recognizes abnormal proteins containing isoAsp residues during protein repair (Chen et al., 2011). Consistently, the conserved Y130 residue, which serves the dual purpose of acting as a Lewis acid and supporting ligand stabilization, is also present in PIMT (Y55). Although, the amino acids mediating isoAsp recognition appear to be conserved with PIMT, the role of the binuclear zinc center in BAPs in cleaving the peptide bond is not conserved in PIMT. Taken together, the results indicate that FiBAP is a thermostable alternative protein repair enzyme that possesses conserved residues for isoAsp residue recognition and for efficient $\mathrm{Zn}^{2+}$-mediated peptide bond hydrolysis.

In contrast to the crystal structures of BAP homologs inactivated by mutations (Thoden et al., 2003; Park et al., 2017), the crystal structure of the ligand-bound form of FiBAP was obtained without any significant cleavage of bound $\beta$-DL (Figures 5A,C,E). This could be explained by various reasons. Firstly, crystallization was carried out at below room temperature $\left(20^{\circ} \mathrm{C}\right)$ in a low-pH buffer $(\mathrm{pH}<5.0)$, which could have affected the enzyme activity (Figures 2C,D). Secondly, we synthesized Cbz- $\beta$-DL dipeptide as a substrate analog inhibitor in which benzyl chloroformate $(\mathrm{Cbz})$ is a carbobenzyloxy protecting group that protects the substrate amino group. Previous studies have shown clearly that $\mathrm{Cbz}$ acts as an inhibitor of several enzymes systems including human alpha-thrombin (De Simone et al., 1997) and sortase cysteine transpeptidase (Jacobitz et al., 2014). Consistently, our substrate analog $(\mathrm{Cbz}-\beta-\mathrm{DL})$ containing $\mathrm{Cbz}$ inhibited enzyme activity in our enzyme assays (data not shown), which suggests that wt FiBAP did not cleave the Cbz- $\beta-\mathrm{DL}$ dipeptide. Therefore, these modifications worked in our favor to obtain the crystal structure of the wild-type enzyme complexed with its substrate. However, the fate of $\mathrm{Cbz}$ in the substratebound enzyme is ambiguous due to the absence of electron density for the $\mathrm{Cbz}$ moiety in the structure. Interestingly, the location of an uncleaved $\beta$-DL based on the electron density map (Figure 5C) coincides precisely with the dipeptide ( $\beta$-AspLys or His) location described in previous studies (Thoden et al., 2003; Marti-Arbona et al., 2005a; Park et al., 2017) (Figure 5E). Thus, it seems probable that the $\mathrm{Cbz}$ entity may be cleaved by hydrogenolysis before the $\mathrm{N}$-terminal end of the dipeptide enters the substrate-binding cavity, since the benzyl ring of $\mathrm{Cbz}$ (if uncleaved) might cause steric hindrance within the cavity. Furthermore, the second amino acid following Asp in the dipeptide (Leu in $\beta$-DL) is unlikely to interact with any surrounding residues of FiBAP (Figures 5D,E).

The primordial FiBAP is a unique metallopeptidase that is presumably involved in the sequestration of unwanted 
forms of peptides. Notably, FiBAP is the most abundant and highly expressed protein when $F$. islandicum AW-1 is grown on feather keratins under starvation conditions (Kang et al., 2020). Although this enzyme is not one of the major endo-type membrane proteases, but rather a protease involved in keratin degradation, its physiological role seems to be important for cellular survival due to the formation of isopeptides that contribute to thermostability, as observed in other anaerobic pathogens (Liu et al., 2016), as well as a providing a source of amino acids for new protein synthesis (Prouty and Goldberg, 1972). The formation of isoAsp residues has received much attention because it is a major structural modification that contributes to the inactivation, aggregation, and malfunction of proteins (Aswad, 1995; Cournoyer et al., 2005). Spontaneous isopeptide bond formation is accelerated at elevated temperatures, and intermolecular amide bonds help proteins to be more thermostable (Zakeri and Howarth, 2010; Si et al., 2016). However, such chemical modifications are not always favorable for cellular viability due to the accumulation of potentially harmful isoAsp peptides in the brain and other tissues (Cantor et al., 2009). Furthermore, balance between the formation and decomposition of isopeptide bonds via isoAsp peptidase is crucial to bacterial survival. Indeed, the growth profiles of the $\triangle l e u B \triangle i a d A$ double mutant of E. coli BL21 clearly indicated that heat shock for 30 min significantly retarded bacterial growth, presumably due to an increase in the accumulation of abnormal proteins (Figure 7A). Notably, expression of FiBAP, even at suboptimal temperatures ranging from 37 to $44^{\circ} \mathrm{C}$, may be sufficient to support bacterial growth through efficient degradation of isoAsp residue-containing proteins. Although the amount of IsoAsp in mutant expressing FiBAP was not decreased as much as in mutant expressing EcIadA, levels of alleviation of growth defect were similar. This result suggests that enzymatic activity of FiBAP is not limited toward isoAsp containing peptides but also includes a broad range of protein aggregates which is related to the interpretation of our MS data (Figures 3, 7B,C, 8).

Unlike BAPs, which are mainly present in extremophiles and several enteric bacteria, PIMT is a conserved and nearly ubiquitous enzyme present in all forms of life that catalyzes the transfer of the methyl group from AdoMet to $\alpha$-carboxyl of an isoAsp site, resulting in the rapid decomposition of methyl esters to succinimide intermediates (Skinner et al., 2000). Therefore, like isoAsp peptidase, PIMT is a useful enzyme for repairing isoAsp damage in all organisms. Nevertheless, when decomposition of isopeptide bonds is a prerequisite for balancing nutrient availability and thermostability under extreme environments, PIMT is unlikely to be an efficient catalyst in terms of the rate of isopeptide decomposition and formation. Indeed, the formation of succinimide by PIMT resulting from isoAsp-containing peptides generates a mixture of isoAsp-Xaa and Asp-Xaa with a stoichiometric ratio of 7:3 (Aswad et al., 2000). However, BAP can directly hydrolyze isopeptide bonds via the $\beta$-carboxylate group of isoAsp, resulting in the release of Asp (MartiArbona et al., 2005a), and this might be a more efficient repair mechanism for handing $\beta$-aspartyl-containing peptides. Furthermore, proteolytic pathways function during starvation to liberate amino acids, and this may be beneficial for dietary protein digestion and cellular protein turnover (Finn and Dice, 2006).

Regarding the functional and physiological roles of FiBAP, we offer two suggestions explaining why this enzyme is conserved in all extremely thermophilic anaerobes, and why it is so abundant in F. islandicum AW-1 during keratin degradation. Firstly, it is one of the key enzymes involved in maintaining proteostasis in thermophiles thriving in harsh environments. By directly hydrolyzing peptide bonds in isoAsp-containing peptides, it can efficiently control aggregated, modified, or damaged proteins, thereby supporting the viability of thermophiles at elevated temperatures. Secondly, under starvation conditions, when insoluble keratins are the only nutrient available for cellular growth, this enzyme may utilize $\beta$-aspartyl peptides as a source of amino acids for protein biosynthesis. This hypothesis is supported by previous studies showing that FiBAP is expressed at high levels under starvation conditions (Kang et al., 2020), suggesting that nutrient depletion acts as a stress condition that stimulates FiBAP expression and enzyme activity. Furthermore, peptidase-deficient $E$. coli leucine auxotrophic strains did not grow in M9 minimal media containing 19 amino acids (Leu ${ }^{-}$) and $\beta$-DL. However, expression of EcIadA or FiBAP enabled the $E$. coli mutant to grow in this medium, implying that FiBAP contribute to increasing the availability of nutrients (Viola, 2001), thereby assisting the maintenance of cellular growth under stressful conditions (Figure 6). Thus, FiBAP may not be a membrane bound endo- or exo-type keratinolytic protease (Kang et al., 2020), but it appears to be strongly associated with the degradation of abnormal proteins as well as intracellular keratin peptides to provide a source of amino acids for protein biosynthesis under stress conditions.

\section{DATA AVAILABILITY STATEMENT}

The original contributions presented in the study are included in the article/Supplementary Material, further inquiries can be directed to the corresponding author/s.

\section{AUTHOR CONTRIBUTIONS}

JL, ID, HJ, SL, and D-WL formulated the research plan, carried out experiments, analyzed and interpreted the data, and drafted the manuscript. JL, ID, SL, and D-WL participated in the design of the study and analyzed and interpreted the data. SL and D-WL conceived, planned, and supervised the study. All authors contributed to the article and approved the submitted version.

\section{FUNDING}

This work was supported by the Strategic Initiative for Microbiomes in Agriculture and Food, funded by the Ministry of Agriculture, Food, and Rural Affairs (918012-4 to D-WL), by the Korea Health Technology R\&D Project through the Korea 
Health Industry Development Institute, funded by the Ministry of Health \& Welfare, Republic of Korea (HP20C0082 to D-WL), by the Yonsei University Research Fund of ICB192021 (201922-0040 to D-WL), and by the National Research Foundation of Korea (NRF-2019R1F1A1049035 to SL).

\section{ACKNOWLEDGMENTS}

We thank Eunju Kang, Jae-Yoon Sung, Keun Young Yoo, Ji-Young Lee, and Hyeon-Su Jin for technical support during

\section{REFERENCES}

Adams, P. D., Afonine, P. V., Bunkóczi, G., Chen, V. B., Davis, I. W., Echols, N., et al. (2010). PHENIX: a comprehensive Python-based system for macromolecular structure solution. Acta Crystallogr. D Biol. Crystallogr. 66 (Pt 2), 213-221. doi: 10.1107/S0907444909052925

Afonine, P. V., Mustyakimov, M., Grosse-Kunstleve, R. W., Moriarty, N. W., Langan, P., and Adams, P. D. (2010). Joint X-ray and neutron refinement with phenix.refine. Acta Crystallogr. D Biol. Crystallogr. 66(Pt 11), 1153-1163. doi: 10.1107/S0907444910026582

Aswad, D. W. (1995). Deamidation and Isoaspartate Formation in Peptides and Proteins. Boca Raton, FL: CRC Press.

Aswad, D. W., Paranandi, M. V., and Schurter, B. T. (2000). Isoaspartate in peptides and proteins: formation, significance, and analysis. J. Pharm. Biomed. Anal. 21, 1129-1136. doi: 10.1016/S0731-7085(99)00230-7

Cantor, J. R., Stone, E. M., Chantranupong, L., and Georgiou, G. (2009). The human asparaginase-like protein 1 hASRGL1 is an Ntn hydrolase with beta-aspartyl peptidase activity. Biochemistry 48, 11026-11031. doi: 10.1021/bi901397h

Chen, B., Retzlaff, M., Roos, T., and Frydman, J. (2011). Cellular strategies of protein quality control. CSH Perspect. Biol. 3:a004374. doi: $10.1101 /$ cshperspect.a004374

Coker, J. A. (2019). Recent advances in understanding extremophiles. F1000Research 8:F1000 Faculty Rev-1917. doi: 10.12688/f1000research.20765.1

Cournoyer, J. J., Pittman, J. L., Ivleva, V. B., E., Fallows, L., Waskell, Costello, C. E., et al. (2005). Deamidation: differentiation of aspartyl from isoaspartyl products in peptides by electron capture dissociation. Protein Sci. 14, 452-463. doi: $10.1110 /$ ps.041062905

De Castro, R. E., Maupin-Furlow, J. A., Giménez, M. I., Herrera Seitz, M. K., and Sánchez, J. J. (2006). Haloarchaeal proteases and proteolytic systems. FEMS Microbiol. Rev. 30, 17-35. doi: 10.1111/j.1574-6976.2005.00003.x

De Simone, G., Balliano, G., Milla, G.allina, C., and Giordano, C., Tarricone, C., et al. (1997). Human $\alpha$-thrombin inhibition by the highly selective compounds N-ethoxycarbonyl-D-Phe-Pro- $\alpha$-azaLys p-nitrophenyl ester and $\mathrm{N}$-carbobenzoxy-pro- $\alpha$-azaLys p-nitrophenyl ester: a kinetic, thermodynamic and x-ray crystallographic study. J. Mol. Biol. 269, 558-569. doi: 10.1006/jmbi.1997.1037

Dobson, C. M. (2003). Protein folding and misfolding. Nature 426, 884-890. doi: $10.1038 /$ nature 02261

Dorer, F. E., Haley, E. E., and Buchanan, D. L. (1968). The hydrolysis of beta-aspartyl peptides by rat tissue. Arch. Biochem. Biophys. 127, 490-495. doi: 10.1016/0003-9861(68)90253-1

Elias, J. E., and Gygi, S. P. (2007). Target-decoy search strategy for increased confidence in large-scale protein identifications by mass spectrometry. Nat. Methods 4, 207-214. doi: 10.1038/nmeth1019

Emsley, P., and Cowtan, K. (2004). Coot: model-building tools for molecular graphics. Acta Crystallogr. D Biol. Crystallogr. 60(Pt 12 Pt 1), 2126-2132. doi: 10.1107/S0907444904019158

Finn, P. F., and Dice, J. F. (2006). Proteolytic and lipolytic responses to starvation. Nutrition 22, 830-844. doi: 10.1016/j.nut.2006.04.008

Gary, J. D., and Clarke, S. (1995). Purification and characterization of an isoaspartyl dipeptidase from Escherichia coli. J. Biol. Chem. 270, 4076-4087. doi: $10.1074 /$ jbc.270.8.4076 protein purification, enzyme activity assay, construction of mutant strains, and differential scanning calorimetry. We thank the staff at beamlines PLS-7A and-11C at the Pohang Light Source (PLS) for technical support during data collection.

\section{SUPPLEMENTARY MATERIAL}

The Supplementary Material for this article can be found online at: https://www.frontiersin.org/articles/10.3389/fmolb. 2020.600634/full\#supplementary-material

Goldberg, A. L. (1972). Degradation of abnormal proteins in Escherichia coli (protein breakdown-protein structure-mistranslation-amino acid analogs-puromycin). Proc. Nat. Acad. Sci. U. S. A. 69, 422-426. doi: $10.1073 /$ pnas.69.2.422

Goldberg, A. L. (2003). Protein degradation and protection against misfolded or damaged proteins. Nature 426, 895-899. doi: 10.1038/nature02263

Hipp, M. S., Kasturi, P., and Hartl, F. U. (2019). The proteostasis network and its decline in ageing. Nat. Rev. Mol. Cell Biol. 20, 421-435. doi: 10.1038/s41580-019-0101-y

Hutt, D., and Balch, W. E. (2010). Cell Biology. The proteome in balance. Science 329, 766-767. doi: 10.1126/science. 1194160

Ichikawa, J. K., and Clarke, S. (1998). A highly active protein repair enzyme from an extreme thermophile: the L-isoaspartyl methyltransferase from Thermotoga maritima. Arch. Biochem. Biophys. 358, 222-231. doi: 10.1006/abbi.199 8.0830

Jacobitz, A. W., Wereszczynski, J., Yi, S. W., Amer, B. R., Huang, G. L., Nguyen, A. V., et al. (2014). Structural and computational studies of the Staphylococcus aureus sortase B-substrate complex reveal a substrate-stabilized oxyanion hole. J. Biol. Chem. 289, 8891-8902. doi: 10.1074/jbc.M113.509273

Jin, H.-S., Park, S. Y., Kim, K., Lee, Y.-J., Nam, G.-W., Kang, N. J., et al. (2017). Development of a keratinase activity assay using recombinant chicken feather keratin substrates. PLoS ONE 12:e0172712. doi: 10.1371/journal.pone.0172712

Kang, E., Jin, H. S., La, J. W., Sung, J. Y., Park, S. Y., Kim, W. C., et al. (2020). Identification of keratinases from Fervidobacterium islandicum AW1 using dynamic gene expression profiling. Microb. Biotechnol. 13, 442-457. doi: 10.1111/1751-7915.13493

Kim, E., Lowenson, J. D., MacLaren, D. C., Clarke, S., and Young, S. G. (1997). Deficiency of a protein-repair enzyme results in the accumulation of altered proteins, retardation of growth, and fatal seizures in mice. Proc. Nat. Acad. Sci. U. S. A. 94, 6132-6137. doi: 10.1073/pnas.94.12.6132

Lee, Y. J., Dhanasingh, I., Ahn, J.-S., Jin, H.-S., Choi, J. M., Lee, S. H., et al. (2015b). Biochemical and structural characterization of a keratin-degrading M32 carboxypeptidase from Fervidobacterium islandicum AW-1. Biochem. Bioph. Res. Commun. 468, 927-933. doi: 10.1016/j.bbrc.2015.11.058

Lee, Y. J., Jeong, H., Park, G. S., Kwak, Y., Lee, S. J., Lee, S. J., et al. (2015a). Genome sequence of a native-feather degrading extremely thermophilic eubacterium, Fervidobacterium islandicum AW-1. Stand. Genomic Sci. 10:71. doi: 10.1186/s40793-015-0063-4

Liu, H., Ray, W. K., Helm, R. F., Popham, D. L., and Melville, S. B. (2016). Analysis of the spore membrane proteome in Clostridium perfringens implicates cyanophycin in spore assembly. J. Bacteriol. 198, 1773-1782. doi: 10.1128/JB.00212-16

Marti-Arbona, R., Fresquet, V., Thoden, J. B., Davis, M. L., Holden, H. M., and Raushel, F. M. (2005a). Mechanism of the reaction catalyzed by isoaspartyl dipeptidase from Escherichia coli. Biochemistry 44, 7115-7124. doi: $10.1021 /$ bi050008r

Marti-Arbona, R., Thoden, J. B., Holden, H. M., and Raushel, F. M. (2005b). Functional significance of Glu-77 and Tyr-137 within the active site of isoaspartyl dipeptidase. Bioorg. Chem. 33, 448-458. doi: 10.1016/j.bioorg.2005.10.002

McCoy, A. J. (2007). Solving structures of protein complexes by molecular replacement with Phaser. Acta Crystallogr. D Biol. Crystallogr. 63(Pt 1), 32-41. doi: $10.1107 /$ S0907444906045975 
Mogk, A., Huber, D., and Bukau, B. (2011). Integrating protein homeostasis strategies in prokaryotes. CSH Perspect. Biol. 3:a004366. doi: $10.1101 /$ cshperspect.a004366

Moreno-Gonzalez, I., and Soto, C. (2011). Misfolded protein aggregates: mechanisms, structures and potential for disease transmission. Semin. Cell. Dev. Biol. 22, 482-487. doi: 10.1016/j.semcdb.2011.04.002

Moriarty, N. W., Grosse-Kunstleve, R. W., and Adams, P. D. (2009). Electronic ligand builder and optimization workbench (eLBOW): a tool for ligand coordinate and restraint generation. Acta Crystallogr. D Biol. Crystallogr. $65(\mathrm{Pt}$ 10), 1074-1080. doi: 10.1107/S0907444909029436

Murshudov, G. N., Skubak, P., Lebedev, A. A., Pannu, N. S., Steiner, R. A., Nicholls, R. A., et al. (2011). REFMAC5 for the refinement of macromolecular crystal structures. Acta Crystallogr. D Biol. Crystallogr. 67(Pt 4), 355-67. doi: 10.1107/S0907444911001314

Nam, G. W., Lee, D. W., Lee, H. S., Lee, N. J., Kim, B. C., Choe, E. A., et al. (2002). Native-feather degradation by Fervidobacterium islandicum AW-1, a newly isolated keratinase-producing thermophilic anaerobe. Arch. Microbiol. 178, 538-547. doi: 10.1007/s00203-002-0489-0

Ogé, L., Bourdais, G., Bove, J., Collet, B., Godin, B., Granier, F., et al. (2008). Protein repair L-isoaspartyl methyltransferase1 is involved in both seed longevity and germination vigor in Arabidopsis. Plant Cell 20:3022. doi: 10.1105/tpc.108.058479

Park, S. H., Lee, C. W., Lee, S. G., Shin, S. C., Kim, H. J., Park, H., et al. (2017). Crystal structure and functional characterization of an isoaspartyl dipeptidase (CpsIadA) from Colwellia psychrerythraea strain 34H. PLoS ONE 12:e181705. doi: 10.1371/journal.pone.0181705

Prouty, W. F., and Goldberg, A. L. (1972). Fate of abnormal proteins in E. coli accumulation in intracellular granules before catabolism. Nat. New Biol. 240, 147-150. doi: 10.1038/newbio240147a0

Reissner, K. J., and Aswad, D. W. (2003). Deamidation and isoaspartate formation in proteins: unwanted alterations or surreptitious signals? Cell Mol. Life. Sci. 60, 1281-1295. doi: 10.1007/s00018-003-2287-5

Robert, X., and Gouet, P. (2014). Deciphering key features in protein structures with the new ENDscript server. Nucleic Acids Res. 42, W320-4. doi: $10.1093 /$ nar/gku316

Rosen, H. (1957). A modified ninhydrin colorimetric analysis for amino acids. Arch. Biochem. Biophys. 67, 10-15. doi: 10.1016/0003-9861(57)90241-2

Ryttersgaard, C., Griffith, S. C., Sawaya, M. R., MacLaren, D. C., Clarke, S., and Yeates, T. O. (2002). Crystal structure of human L-isoaspartyl methyltransferase. J. Biol. Chem. 277, 10642-10646. doi: 10.1074/jbc.M200229200

Schubert, U., Antón, L. C., Gibbs, J., Norbury, C. C., Yewdell, J. W., and Bennink, J. R. (2000). Rapid degradation of a large fraction of newly synthesized proteins by proteasomes. Nature 404, 770-774. doi: 10.1038/35008096

Shilov, I. V., Seymour, S. L., Patel, A. A., Loboda, A., Tang, W. H., Keating, S. P., et al. (2007). The Paragon algorithm, a next generation search engine that uses sequence temperature values and feature probabilities to identify peptides from tandem mass spectra. Mol. Cell. Proteom. 6:1638. doi: 10.1074/mcp.T600050-MCP200

Si, M., Xu, Q., Jiang, L., and Huang, H. (2016). SpyTag/SpyCatcher cyclization enhances the thermostability of firefly luciferase. PLoS ONE 11:e0162318. doi: 10.1371/journal.pone.0162318

Singleton, R. Jr., and Amelunxen, R. E. (1973). Proteins from thermophilic microorganisms. Bacteriol. Rev. 37, 320-342. doi: 10.1128/MMBR.37.3.320-342.1973

Skinner, M. M., Puvathingal, J. M., Walter, R. L., and Friedman, A. M. (2000). Crystal structure of protein isoaspartyl methyltransferase: a catalyst for protein repair. Structure 8, 1189-1201. doi: 10.1016/S0969-2126(00)00522-0

Smith, P. K., Krohn, R. I., Hermanson, G. T., Mallia, A. K., Gartner, F. H., Provenzano, M. D., et al. (1985). Measurement of protein using bicinchoninic acid. Anal. Biochem. 150, 76-85. doi: 10.1016/0003-2697(85) 90442-7

Tanaka, Y., Tsumoto, K., Yasutake, Y., Umetsu, M., Yao, M., Fukada, H., et al. (2004). How oligomerization contributes to the thermostability of an archaeon protein. Protein L-isoaspartyl-O-methyltransferase from Sulfolobus tokodaii. J. Biol. Chem. 279, 32957-32967. doi: 10.1074/jbc.M404405200

Thoden, J. B., Marti-Arbona, R., Raushel, F. M., and Holden, H. M. (2003). Highresolution X-ray structure of isoaspartyl dipeptidase from Escherichia coli. Biochemistry 42, 4874-4882. doi: 10.1021/bi034233p

Vagin, A., and Teplyakov, A. (2010). Molecular replacement with MOLREP. Acta Crystallogr. D Biol. Crystallogr. 66(Pt 1), 22-25. doi: $10.1107 /$ S0907444909042589

Viola, R. E. (2001). The central enzymes of the aspartate family of amino acid biosynthesis. Acc. Chem. Res. 34, 339-349. doi: 10.1021/ar000057q

Visick, J. E., and Clarke, S. (1995). Repair, refold, recycle: how bacteria can deal with spontaneous and environmental damage to proteins. Mol. Microbiol. 16, 835-845. doi: 10.1111/j.1365-2958.1995.tb02311.x

Zakeri, B., and Howarth, M. (2010). Spontaneous intermolecular amide bond formation between side chains for irreversible peptide targeting. J. Am. Chem. Soc. 132, 4526-4527. doi: 10.1021/ja910795a

Conflict of Interest: The authors declare that the research was conducted in the absence of any commercial or financial relationships that could be construed as a potential conflict of interest.

Copyright (c) 2020 La, Dhanasingh, Jang, Lee and Lee. This is an open-access article distributed under the terms of the Creative Commons Attribution License (CC BY). The use, distribution or reproduction in other forums is permitted, provided the original author(s) and the copyright owner(s) are credited and that the original publication in this journal is cited, in accordance with accepted academic practice. No use, distribution or reproduction is permitted which does not comply with these terms. 